This item was submitted to Loughborough's Research Repository by the author.

Items in Figshare are protected by copyright, with all rights reserved, unless otherwise indicated.

\title{
The impact of intake pressure on high exhaust gas recirculation low- temperature compression ignition engine combustion using borescopic imaging
}

\section{PLEASE CITE THE PUBLISHED VERSION}

https://doi.org/10.1177/1468087420926024

PUBLISHER

SAGE PUBLICATIONS LTD

\section{VERSION}

AM (Accepted Manuscript)

\section{PUBLISHER STATEMENT}

This paper was accepted for publication in the journal International Journal of Engine Research and the definitive published version is available at https://doi.org/10.1177/1468087420926024

\section{LICENCE}

In Copyright

\section{REPOSITORY RECORD}

Sarangi, AK, Colin Garner, GP McTaggart-Cowan, MH Davy, and Graham Hargrave. 2021. "The Impact of Intake Pressure on High Exhaust Gas Recirculation Low-temperature Compression Ignition Engine Combustion Using Borescopic Imaging". Loughborough University. https://hdl.handle.net/2134/13607774.v1. 


\title{
The impact of intake pressure on high-EGR low temperature compression ignition engine combustion using borescopic imaging
}

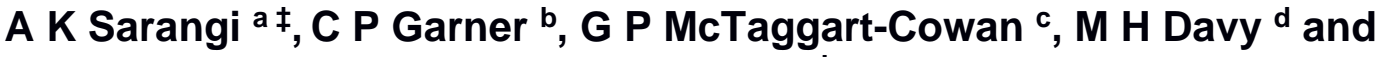 G K Hargrave ${ }^{b}$}

\author{
a Indian Institute of Technology Bombay, Mumbai, India \\ ₹ Corresponding author e-mail: asish.sarangi@iitb.ac.in \\ b Loughborough University, Loughborough, UK \\ c Simon Fraser University, Surrey, Canada \\ d University of Oxford, Oxford, UK
}

\begin{abstract}
In diesel engines high levels of exhaust gas recirculation (EGR) can be used to achieve low temperature combustion, resulting in low emissions levels of both nitrogen oxides (NOx) and particulate matter. This work studied the effects of varying the intake manifold pressure on in-cylinder combustion processes and engine-out emissions from a light-duty single cylinder diesel engine under conventional and high-EGR low temperature combustion regimes. The work was conducted at a part-load cruise condition of $1500 \mathrm{rpm}$ and at an indicated mean effective pressure of approximately $600 \mathrm{kPa}$. EGR rates were varied between $0-65 \%$ at absolute intake pressures of $100-150 \mathrm{kPa}$. Very low NOx emissions were achieved $(<10 \mathrm{ppm}, \sim 0.05 \mathrm{~g} / \mathrm{kWh}$ ) for intake oxygen mass fractions below about $11 \%$, independent of boost pressure. Smoke emission levels were lower than for non-EGR combustion at oxygen mass fractions below $\sim 9 \%$, depending on the boost pressure. High intake pressures reduced fuel consumption by $15 \%$ and combustion by-product emissions by $50-60 \%$ compared to low boost. For the low intake boost case, little visible flame was apparent through borescope imaging. At higher boost pressures, intense flame luminosity was observed within the piston bowl early in the expansion stroke. Spatially averaged soot luminosity based on photomultiplier tube data showed that peak soot luminosity was five times greater and occurred eight crank angle degrees earlier for high boost. This work demonstrates how the combination of appropriate boost pressures and EGR rates can be used to mitigate the emissions and thermal efficiency penalties of high-dilution low temperature combustion to achieve near-zero NOx operation.
\end{abstract}

Keywords: $\mathrm{NO}_{\mathrm{x}}$; EGR; Low temperature combustion; Flame luminosity; Borescope; Diesel low temperature combustion (LTC) 


\section{Introduction}

Diesel engines are used extensively in both on- and off-road vehicles and in stationary power applications owing to their high thermal efficiency and durability. Diesel engines' high efficiency results in lower carbon dioxide $\left(\mathrm{CO}_{2}\right)$ emissions per unit energy than for other types of engine used for motive power. However, untreated diesel engine exhaust gases typically contain significant quantities of nitrogen oxides $\left(\mathrm{NO}_{\mathrm{X}}\right)$ and particulate matter $(\mathrm{PM})$. In most circumstances, NOx and PM emissions can be controlled to most current legislated emissions levels through a combination of complex exhaust aftertreatment devices and in-cylinder combustion optimization. However, to meet future emissions requirements, controlling engine-out NOx during cold-start or in off-cycle conditions where the aftertreatment is not active will be critical. Exhaust gas recirculation (EGR), which reduces the in-cylinder oxygen concentration and hence the local flame temperature, can significantly reduce NOx, although this traditionally comes at the expense of increased PM emissions [1]. The current work uses combined optical and thermodynamic techniques to evaluate using high levels of EGR to achieve near-zero NOx emissions through low temperature combustion (LTC) while using boost pressure to control PM in a light-duty diesel engine under part-load conditions.

At present, typical EGR levels in production diesel engines are limited to relatively low levels (15$20 \%$ at high load, up to $\sim 30 \%$ at low load). While further NOx reductions could be achieved by higher EGR levels, these are offset by increases in PM and reduced engine efficiency. It is reported that at an EGR rate of about $40 \%$, a very low luminous intensity was observed for an advanced injection conventional diesel case [2]. A comprehensive review elucidating the effects of EGR on advanced diesel combustion is provided by Thangaraja and Kannan [3]. The use of very high EGR rates ( $>50 \%)$ has been investigated as a technique to achieve LTC, in which local temperatures are so low that both NOx and PM are near-zero. The long diesel ignition delay associated with high EGR levels leads to improved premixing of the diesel, resulting in local equivalence ratios in the reaction zones below the levels needed to form soot precursors. High-EGR diesel LTC combines high levels (up to 60\%) of EGR with substantially modified fuel injection timing compared to conventional diesel engines for the control of combustion phasing. As a consequence of the reduced flame temperature and lower in-cylinder oxygen concentrations found in LTC, it is usual for the emissions of unburned total hydrocarbons (THC) and carbon monoxide (CO) emissions to increase significantly. This effect has been demonstrated for a wide range of different LTC strategies including homogeneous charge compression ignition LTC [4, 5], 
moderate EGR split injection LTC [6, 7], single injection high-EGR LTC/partially premixed compression ignition LTC $[8,9,10,11,12]$, premixed charge compression ignition LTC [13, 14] and reactivity controlled compression ignition LTC [15, 16]. Less homogeneous charge distribution, including locally fuel-lean and fuel-rich regimes, leads to a more stratified combustion process in highEGR LTC compared to homogeneous charge approaches. These processes will tend to smooth the rate of combustion, as well as reducing sensitivity to small variations in ignition and combustion rate [8, 17].

Due to slow combustion rates and the high level of dilution needed to achieve high-EGR LTC, this strategy is typically limited to part-load conditions. One approach that can offset some limitations of the high-EGR LTC strategy at higher loads is to increase intake manifold pressures (boost). There are only a limited number of studies investigating the effects of boost on the performance and emissions in automotive engines operating in LTC modes, e.g. advanced injection high-EGR LTC [18, 19], advanced injection moderate-EGR LTC [10], late injection moderate-EGR LTC [18] and with intermediate EGR levels (while transitioning from conventional diesel to high-EGR LTC) [20]. In all these cited references it was shown that increased boost in high-EGR LTC improved combustion efficiency and specific fuel consumption. In a previous paper [19], the authors have demonstrated reduced THC, CO and smoke emissions and gross indicated specific fuel consumption (GISFC) without impact on NOx emissions in the high-EGR LTC strategy with increased boost pressure. This was hypothesised to be a result of higher boost increasing local temperatures and oxygen concentrations in the cylinder during the later stages of the combustion event, which would be expected to increase oxidation of soot, soot precursors and combustion by-products. Based on the in-cylinder pressure data available in [19], this could not be conclusively proven: further evaluation, using detailed in-cylinder assessment, was needed to better understand this critical question. Moreover, in all the cited studies that involved both thermodynamic and optical assessment of high-EGR LTC $[2,8,10,12,18]$ the thermodynamic and optical measurements were not directly comparable as they were conducted in different engines. Typically, the optical tests have been conducted on engines with non-representative piston bowl geometries; for example, the work of Colban et al. [18], Han et al. [10], Musculus et al. [8], Jung et al. [12] and Lee et al. [2] used a flatbottom piston that will have significantly impacted the interaction between the diesel spray and the wall, and correspondingly the charge preparation. Other combined optical and thermodynamic studies used simulated EGR, including dilution with $\mathrm{N}_{2}[10,12]$ or a mixture of air, $\mathrm{N}_{2}$, and $\mathrm{CO}_{2}[2,18]$ to achieve the target dilution levels. It is well known that the lack of water vapour and other species included in 
'real' EGR will impact the charge heat capacity and chemical processes [1]; these effects will be especially important at high dilution levels.

The current study aims to provide the first detailed investigation of high EGR LTC where engine performance and emissions data are combined with optical assessment on identical hardware while also using real EGR to achieve identical operating conditions for both optical and non-optical (thermodynamic) assessments. This work provides new insights into both conventional diesel and low temperature combustion, including important new information on soot behaviour and strong evidence to support the use of controlled boost pressures and EGR rates for delaying the onset of bulk quenching in high-EGR LTC engine operation that was hypothesised to be the main factor towards reducing the THC, $\mathrm{CO}$ and smoke emissions. Previous studies have focused on visible in-cylinder flame luminosity in the early parts of the mixing-controlled combustion phase of high-EGR combustion. However, the rapid decay in flame luminosity in the later part of the mixing-controlled combustion results in a lack of insight during the late stage 'tail' of the energy release. In this work, for the first time, in-cylinder imaging is combined with measurement of the temporal flame luminosity at a fixed wavelength, using an amplified photomultiplier tube to evaluate the post premixing combustion phase. These results are then directly related to observed engine performance and emissions results, to provide a comprehensive new understanding of this important phase of high-EGR, low-temperature combustion.

The aim of the work reported here was to investigate the effects of intake pressure on combustion and emissions during the transition to high-EGR LTC operation. The principal objectives were, first, to define the transition from conventional diesel to low temperature combustion at fixed fuelling rate for selected boost pressures. Second, the sensitivity of the combustion behaviour for high-dilution LTC to boost pressure was to be determined through combined thermodynamic and optical measurements. Finally, key features of the in-cylinder processes that distinguish high-dilution LTC from conventional diesel combustion were to be identified using comparative in-cylinder observations. The potential impact of the work is to demonstrate that, by appropriately defining the operating conditions, ultra-low NOx emissions can be achieved at light- and medium-loads, where conventional diesel engines emit high levels of NOx and where exhaust temperatures are marginal for achieving high NOx conversion in exhaust after-treatments systems. 


\section{Experimental Set Up}

This work used an AVL 5402 research engine, a single cylinder version of a typical two-litre fourcylinder light-duty high speed direct injection (HSDI) diesel engine. It featured a central fuel injector in a four-valve, dual-overhead cam configuration. One exhaust valve was removed to allow optical access into the combustion chamber. Diesel fuel (ultra-low sulphur diesel as per BS EN590) was injected using a Bosch common rail fuel injection system, while fuel temperature was controlled using an AVL fuel conditioning unit. A custom gas exchange system (Fig. 1) controlled intake charge pressure and temperature (accuracies $\pm 1 \mathrm{kPa}$ and $\pm 3^{\circ} \mathrm{C}$ respectively), exhaust back-pressure (accuracy $\pm 1 \mathrm{kPa}$ ), and the flow and temperature of EGR (accuracies $\pm 0.5 \%$ and $\pm 3{ }^{\circ} \mathrm{C}$ respectively). Specifications of the engine and associated systems are given in Table 1, and are discussed in more detail in previous publications $[19,21,22]$

Table 1: Single cylinder research engine and fuelling system specifications [19, 21, 22]

\begin{tabular}{|c|c|}
\hline \multicolumn{2}{|c|}{ Research Engine } \\
\hline Engine type & AVL 5402 Single cylinder diesel \\
\hline Bore/Stroke/Connecting rod length & $85 / 90 / 148 \mathrm{~mm}$ \\
\hline Swept volume & 0.51 litre \\
\hline Compression ratio & 17.1:1 \\
\hline Rated speed & $4200 \mathrm{rpm}$ \\
\hline Swirl ratio (nominal) & 1.78 \\
\hline Combustion chamber geometry & Re-entrant bowl \\
\hline Intake ports & Tangential and swirl \\
\hline \multicolumn{2}{|c|}{ Fuelling System } \\
\hline Injection system & Bosch common rail \\
\hline Maximum rail pressure & $135 \mathrm{MPa}$ \\
\hline Nozzle type & Valve covered orifice (VCO) \\
\hline Number of holes/Diameter & $5 / 0.18 \mathrm{~mm}$ \\
\hline Spray included angle & $142^{\circ}$ \\
\hline \multicolumn{2}{|c|}{ Fuel * } \\
\hline Density at $15^{\circ} \mathrm{C}$ & $840 \mathrm{~kg} \cdot \mathrm{m}^{-3}$ \\
\hline $\begin{array}{l}\text { Polycyclic aromatic hydrocarbon } \\
\text { (PAH) }\end{array}$ & $9 \%$ \\
\hline Sulphur content & $8 \mathrm{mg} \cdot \mathrm{kg}^{-1}$ \\
\hline Cetane number & 52 \\
\hline
\end{tabular}

* Values provided by the supplier

The research facility was fully instrumented to measure air temperature (accuracy $< \pm 1.3^{\circ} \mathrm{C}$ ) and pressure (accuracy $<0.3 \%$ full scale sensor output), fuel and air flow rates (accuracy $\pm 0.12 \%$ and $0.5 \%$ of reading respectively), and in-cylinder pressure (accuracy $\pm 0.2 \%$ full scale sensor output). Piston 
position was measured with an AVL365 crank-angle encoder with a resolution of $0.5^{\circ} \mathrm{CA}$. At least 200 consecutive cycles of in-cylinder pressure data were collected. The average cylinder pressure was used to estimate the energy release rates using the first-law of thermodynamics [23]. Integrating the net energy release up to a certain crank angle and normalising it by the cumulative energy release provided the fraction of energy release up to that point. Typical points of interest in this work included the phasing of the $10 \%, 50 \%$ and $90 \%$ values of the cumulative energy release (designated CA10, CA50 and CA90, respectively). The start of combustion (SOC) was identified as the start of the main energy release, excluding the 'cool-flame' phase. Ignition delay was defined as the time (in ${ }^{\circ} \mathrm{CA}$ ) between the commanded start of fuel injection and the SOC. Gaseous emissions were measured with a Horiba MEXA 7100HEGR bench (accuracies: $\mathrm{CO}, 50 \mathrm{ppm}$; NOx, $10 \mathrm{ppm} ; \mathrm{CO}_{2}, 0.5 \%$; THC $10 \mathrm{ppm}$ ), including intake manifold $\mathrm{CO}_{2}$, which was used to calculate the EGR rate. Smoke emissions were measured with an AVL415 smoke meter (accuracy: $\pm 3.5 \%$ ) and are reported here as raw filter smoke number (FSN), providing a relative concentration of soot.

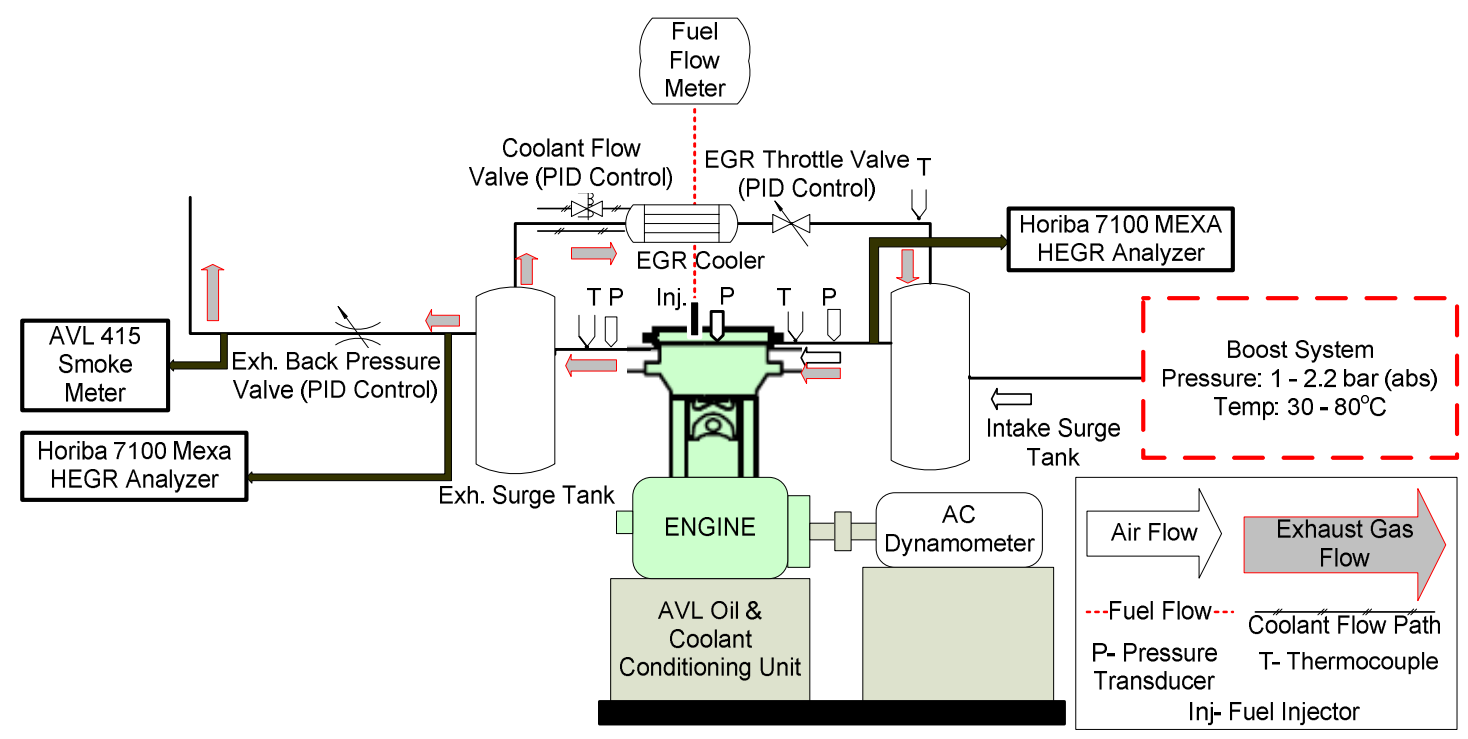

Fig. 1: Schematic of the research engine facility and gas exchange system

For in-cylinder spray and combustion visualization, a pair of AVL fused silica optical windows were inserted through the deactivated valve in the cylinder head and protruded slightly into the combustion chamber. Cut-outs were machined in the piston lip to provide clearance from the protruding optical windows. To ensure that the cylinder clearance volume was consistent whether or not optical testing was being conducted, dummy plugs with the same geometry as the windows were installed when 
optical access was not needed. The windows provided access for a cooled borescope with a wide-angle lens and separate illumination through an optical fibre bundle connected to an external strobe. The imaging borescope was connected to a Prosilica GC1380 monochrome charge coupled device (CCD) camera to provide spray and combustion imaging within the borescope's field of view (FOV). The specifications of the various optical components used in the experimental set up are given in Table 2; more information is available elsewhere [22, 24, 25].

Table 2: Specifications of the optical components [22, 24, 25]

\begin{tabular}{|l|l|}
\hline Components & Make/Model \\
\hline Borescope & Karl-Storz/84583A \\
\hline Camera & Prosilica/GC1380 \\
\hline Stroboscope & Perkin Elmer/CX1200 \\
\hline Interference filter & Thorlabs/FB05700-10-SP \\
\hline Amplified photomultiplier tube module & Hamamatsu/H5784-20 \\
\hline
\end{tabular}

The region inside the piston bowl imaged through the borescope at different crank angles is shown in Fig. 2. The schematic also shows the FOV including the orientation of a diesel spray. The orientation of the installation tube generated a FOV that was centred on the axis of one of the diesel sprays from the injector. Alignment grids and letters drawn on the piston bowl and the top land can be seen in the figure. In the region near top dead centre (TDC, $\pm 30^{\circ} \mathrm{CA}$ ATDC), only the piston bowl is visible in the FOV of the borescope. Beyond this crank angle, a part of the squish region (piston top land) could also be seen.

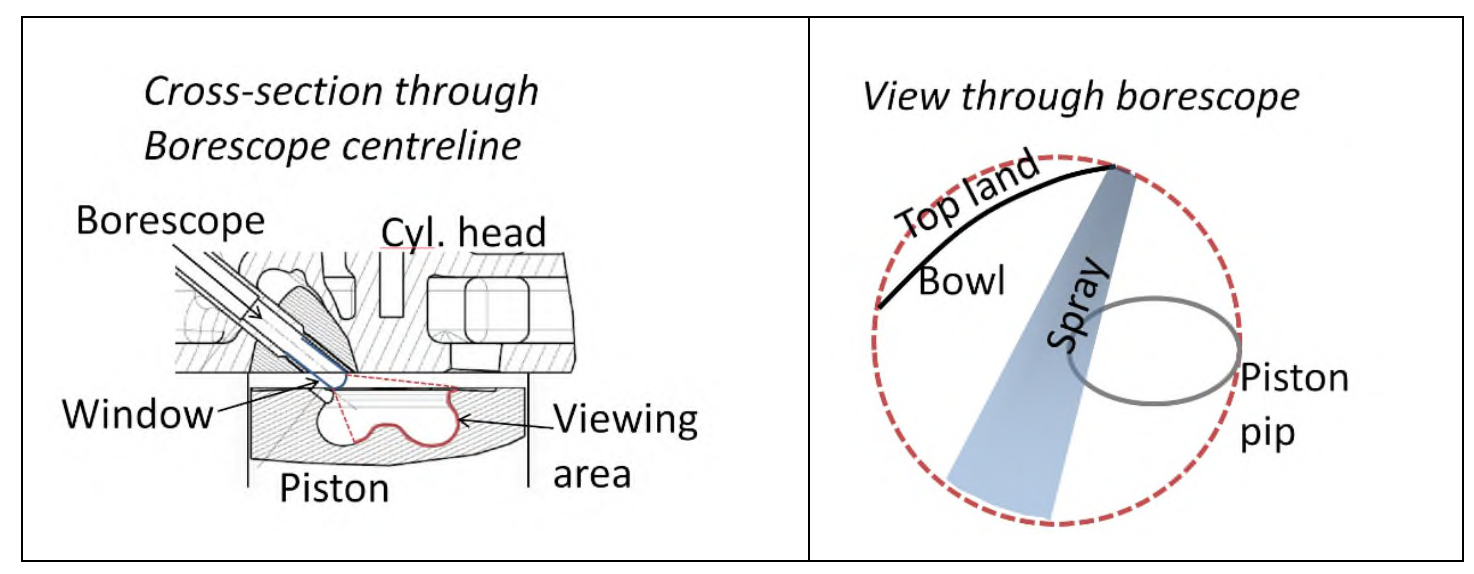




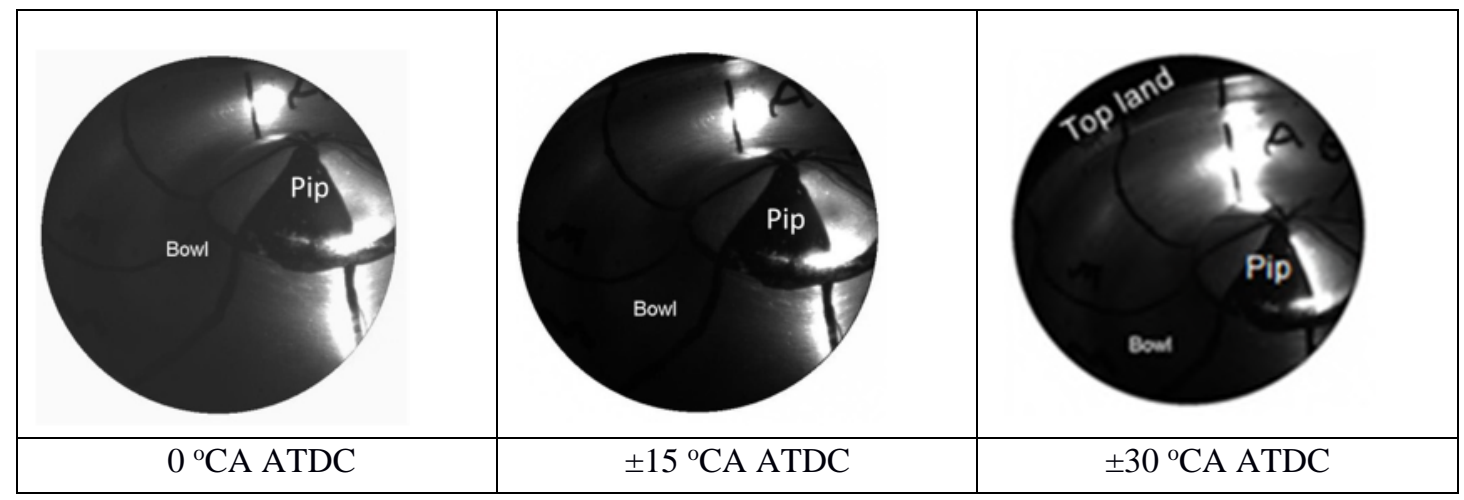

Fig. 2: Schematic representation of the 2-D field of view of the borescope, showing the visible regions of the piston crown and the location of the diesel spray when viewed through the borescope. Borescope photos show the effects of the changes in piston height with crank angle.

The borescope was also used to capture field of view integrated soot radiation intensity. A 700 nm interference filter was coupled with a Hamamatsu amplified photomultiplier tube to measure soot radiation. The $700 \mathrm{~nm}$ filter was used to avoid confounding the soot radiation with natural chemiluminescence from, for example, $\mathrm{CH}$ radicals (390 and $431.5 \mathrm{~nm}$ ), $\mathrm{C}_{2}$ radicals $(473.7$ and 516.5 $\mathrm{nm}$ ), and formaldehyde, $\mathrm{CH}_{2} \mathrm{O},(395.2 \mathrm{~nm}$, and broadband between 422 and $440 \mathrm{~nm})$ [26]. The wide FOV of the borescope used in this work ensured that there was a better chance of capturing soot incandescence within the piston bowl late during the combustion process and in the less luminous LTC regime, although reactions occurring in the squish region were not captured. Similar to the in-cylinder pressure, the photomultiplier tube (PMT) voltage output data reported here is the average of 200 consecutive cycles.

\section{Operating Conditions}

For this work, the sensitivity of engine performance and emissions over a range of EGR levels and boost pressures was assessed at an engine condition representative of medium-load cruise in a lightduty application [20], described in Table 3. Note that the optical configuration of the engine did not impact the $1500 \mathrm{rpm}$ engine speed choice. The modified engine, with borescopic access, could be operated at higher engine speeds (up to $4200 \mathrm{rpm}$ ) [27]. The effect of boost pressure on the combustion process at high-EGR conditions, with low NOx and low-PM levels representative of LTC, was then evaluated in detail using the optical probe. To drive the EGR, the exhaust back pressure was maintained approximately $20 \mathrm{kPa}$ above the intake pressure. To avoid condensation in the intake manifold, the EGR 
was only partially cooled $\left(>115^{\circ} \mathrm{C}\right)$; this resulted in intake temperatures increasing as a function of EGR and reaching values between $70^{\circ} \mathrm{C}$ and $80^{\circ} \mathrm{C}$ at the highest tested EGR levels. It was shown in a previous publication [28] that at the same engine operating condition but without boost pressure, that minor changes in the intake temperature $\left(80 \pm 10^{\circ} \mathrm{C}\right)$ had a negligible influence on most aspects of the combustion processes and emissions in the high-EGR LTC strategy. The engine lubricating oil and coolant temperatures were maintained at $90 \pm 1^{\circ} \mathrm{C}$ and $85 \pm 1^{\circ} \mathrm{C}$, respectively.

Table 3: Operating conditions

\begin{tabular}{|l|l|}
\hline Engine speed & $1500 \mathrm{rpm}$ \\
\hline Fuelling quantity & $16 \mathrm{mg} /$ cycle \\
\hline Intake pressure & $100,120,150 \mathrm{kPa}$ (absolute) \\
\hline Injection pressure & $90 \mathrm{MPa}$ \\
\hline EGR & $0-65 \%$ \\
\hline
\end{tabular}

\section{Results and Discussion}

The initial sweeps of EGR at varying boost pressure were used to define the transition from conventional diesel combustion to the low-NOx, low-soot regime characteristic of LTC [20]. High soot concentrations during this transitional regime, which caused rapid fouling of the optical windows, meant that extended operation to collect in-cylinder optical measurements under these conditions were not possible. Optical assessment was conducted at the low-soot concentrations achieved with the LTC operating mode, where optical window fouling was less of a restriction.

\subsection{Effect of boost pressure with increasing EGR rates}

As EGR is increased to transition to LTC operation under different boost levels, the exhaust oxygen concentrations vary. This means that EGR fraction does not directly correlate with charge dilution; using intake oxygen mass fraction $\left(\mathrm{YO}_{2}\right)$ avoids this influence. As dilution is increased at fixed fuelling, the fuel-oxygen based equivalence ratios increase; these are plotted with respect to $\mathrm{YO}_{2}$ in Fig. 3 for three different intake pressures. For these conditions, EGR rates ( $\%$ volume) varied between 0 and $65 \%$. For each test point, the start of injection (SOI) timing was adjusted to maximise thermal efficiency with the restriction of maintaining maximum rate of pressure rise $<1 \mathrm{MPa} /{ }^{\circ} \mathrm{CA}$. With increased charge dilution (decreasing $\mathrm{YO}_{2}$ ) advanced SOI brings the energy release rate towards the TDC; therefore, the fuel to work conversion efficiency is improved, leading to lower indicated specific fuel consumption 
(ISFC) [7, 18, 19] compared to the constant combustion phasing strategy [19]. For 'conventional' diesel combustion (EGR levels $<\sim 30 \%$ ), a small (1.5 mg/injection) diesel pilot was used to reduce pressure rise rates, as is typical in modern diesel engine calibrations. At higher EGR levels, rate of pressure rise was not a limitation; so a pilot injection was not used.

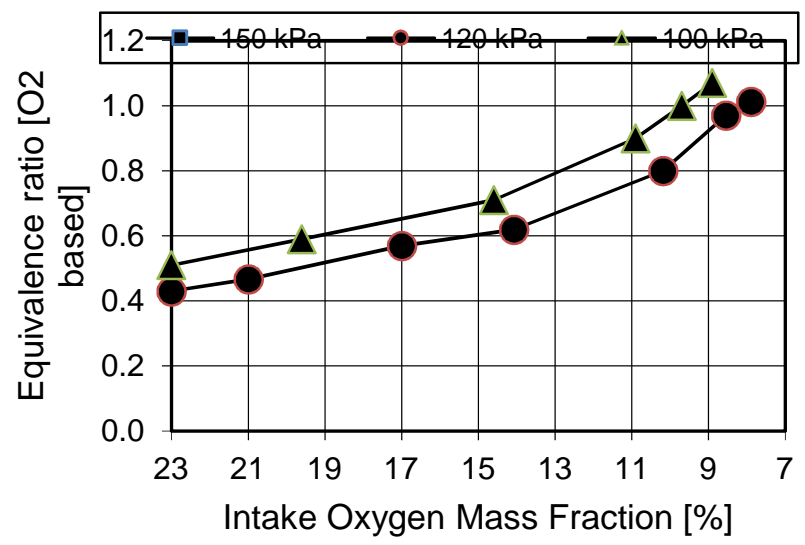

Fig. 3: Variations of global fuel-oxygen equivalence ratio as a function of intake oxygen mass fraction at the tested intake pressures

The baseline, non-EGR engine operating condition was defined on the basis of maximum thermal efficiency as constrained by rate-of-pressure rise. This led to relatively early main injections and advanced combustion phasing (defined by CA50), as shown in Figure 4. As EGR rates increased (lower intake oxygen mass fractions) SOI phasing for best thermal efficiency was advanced, but the CA50 was delayed due to longer ignition delays and slower overall combustion rates. As the main injection duration $\left(6{ }^{\circ} \mathrm{CA}\right)$ was fixed for all cases, the end of injection relative to the start of injection was fixed. At low dilution levels, the combustion starts before the end of injection, but at high dilutions, ignition is well after EOI. The EOI is shown as a horizontal line in Fig. 4, which shows ignition timing relative to SOI. With increased dilution, the ignition delay increases due to both a reduction of the in-cylinder temperature, due to the lower specific heat ratio of EGR, and due to the lower intake oxygen concentration; the latter effect is expected to be dominant [29]. 

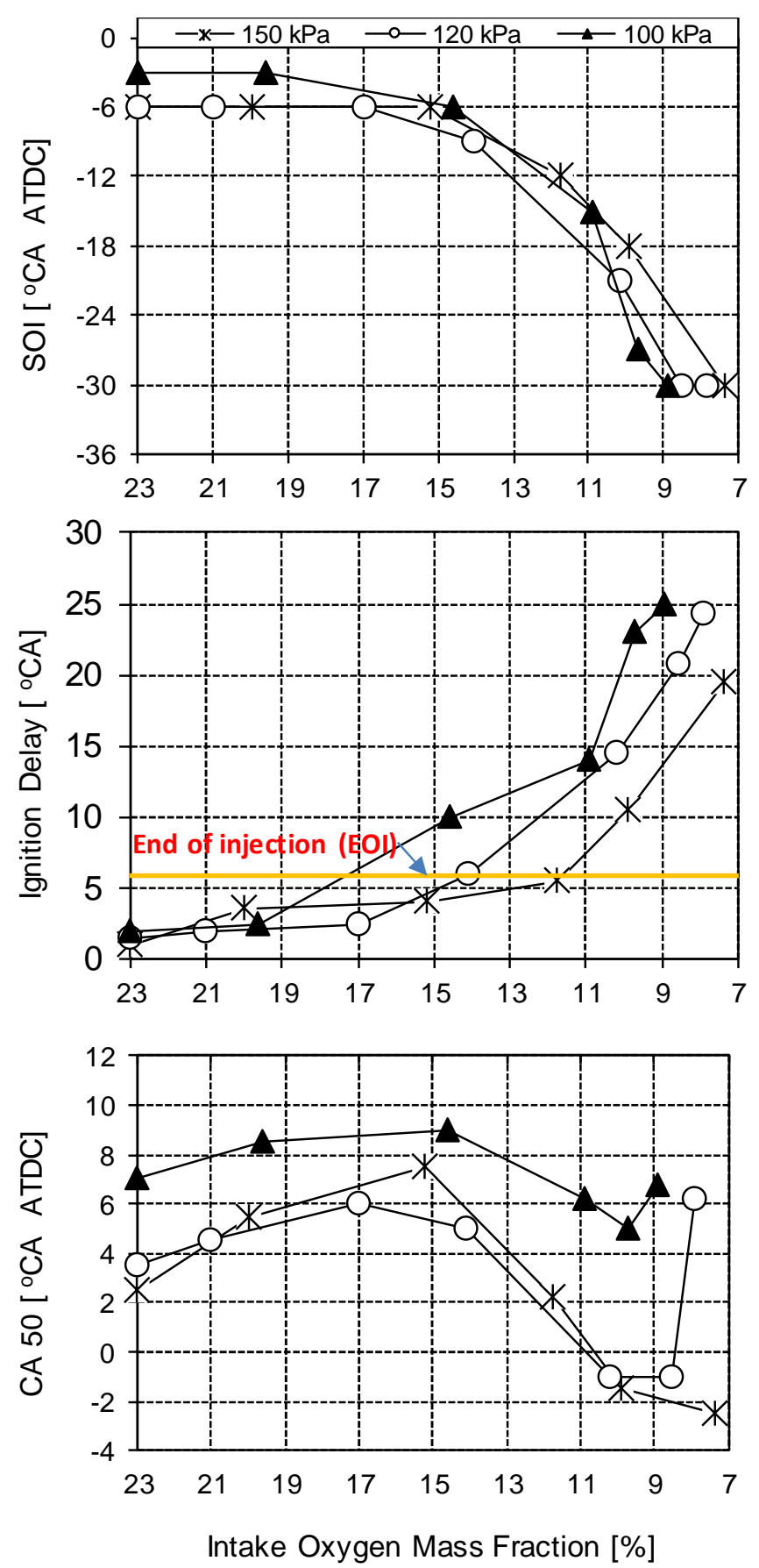

Fig. 4: Variations of the commanded SOI, ignition delay and CA50 with intake oxygen mass fraction at variable intake pressures. The injection delay (commanded SOI-actual SOI) and injection duration (actual SOI-actual EOI) are $1.5{ }^{\circ} \mathrm{CA}(0.167 \mathrm{~ms})$ and $6{ }^{\circ} \mathrm{CA}(0.67 \mathrm{~ms})$ respectively.

At intake oxygen mass fractions below $\sim 15 \%$ for all three boost conditions, the injection was significantly advanced and ignition delay increased substantially, leading to a high degree of premixing of the diesel fuel before ignition occurred. SOIs were relatively consistent across the different boost pressures studied. Higher boost pressures did result in shorter ignition delays, likely due to the increased 
oxygen entrainment rate because of larger concentrations of oxygen in the cylinder and higher gas pressure and density during the injection event, for a given intake oxygen mass fraction [10, 18, 29]. This led to earlier CA50s, especially under highly-dilute conditions $\left(\mathrm{YO}_{2}<9 \%\right)$, where the SOI for all boost pressures was constant at $-30{ }^{\circ} \mathrm{CA}$ ATDC. At intermediate dilution levels (from $\mathrm{YO}_{2} 11 \%-17 \%$ ), ignition delays were longer at the lowest boost pressure (100 kPa) compared to the higher pressures for a given dilution level. Differences between $120 \mathrm{kPa}$ and $150 \mathrm{kPa}$ boost were marginal, compared to the differences with the $100 \mathrm{kPa}$ case. As the SOI was varied at different dilution levels in response to rate of pressure rise limits, combustion phasing did advance even at the lowest boost pressures at higher dilution levels $\left(\mathrm{YO}_{2} \sim 11 \%\right)$. The high-boost cases still had earlier CA50 compared to low-boost, despite generally similar SOIs: this was a result of the shorter ignition delay.

In non-EGR conventional diesel combustion regimes, NOx emissions increased with higher intake pressures, as shown in Fig. 5, due to elevated reaction zone temperatures associated with more advanced combustion phasing (CA50, shown in Fig. 4). As would be expected, diluting the charge with increasing levels of EGR resulted in significant NOx emissions reductions, reaching levels below 10 $\operatorname{ppm}(<0.05 \mathrm{~g} / \mathrm{kWh})$ for intake oxygen mass fractions below $11 \%$, irrespective of intake pressure. Smoke emissions increased over this range, reaching a maximum at oxygen mass fractions in the range of 12 $15 \%$, consistent with $[10,18,19]$. Through simulation, it was shown that at the intermediate EGR levels, the in-cylinder temperature was not low enough to avoid soot formation but did reduce soot oxidation, increasing engine-out soot emissions. With increased dilution (beyond the intermediate EGR levels), the local in-cylinder conditions were displaced towards the low temperature region, avoiding soot formation [9]. Higher boost pressures resulted in lower smoke emissions for a given charge dilution, due to the presence of extra oxygen in the cylinder as demonstrated by the lower global equivalence ratio (Fig. 3). The peak smoke emission shifted towards lower intake oxygen mass fraction with increased intake pressure. This correlates with the shorter ignition delay times that would leave less time for the injected fuel to premix before combustion, leading to more fuel being at the richer local compositions conducive to soot formation. At intake oxygen mass fractions below $\sim 12 \%$, smoke emissions decreased rapidly. Longer ignition delays led to higher premixing of the injected fuel and reduced reaction-zone temperatures, reducing the particulate precursors' formation rate. At the lowest oxygen mass fractions tested (between 7\% and 9\%), filter smoke number (FSN) levels were similar to the non-EGR case, as has been reported in previous publications [10, 12, 19]. It should be noted that equal FSN levels do not mean 
equivalent mass or number of PM: prior work has shown that the composition and morphology of engineout soot from LTC can differ significantly from that of conventional diesel [30]. Despite this, the results demonstrate that low-soot, near-zero NOx conditions, as typically associated with LTC, were achieved at all intake pressures. Higher levels of charge dilution were needed to reach this condition with higher intake pressures, which is consistent with previous research [18, 19].
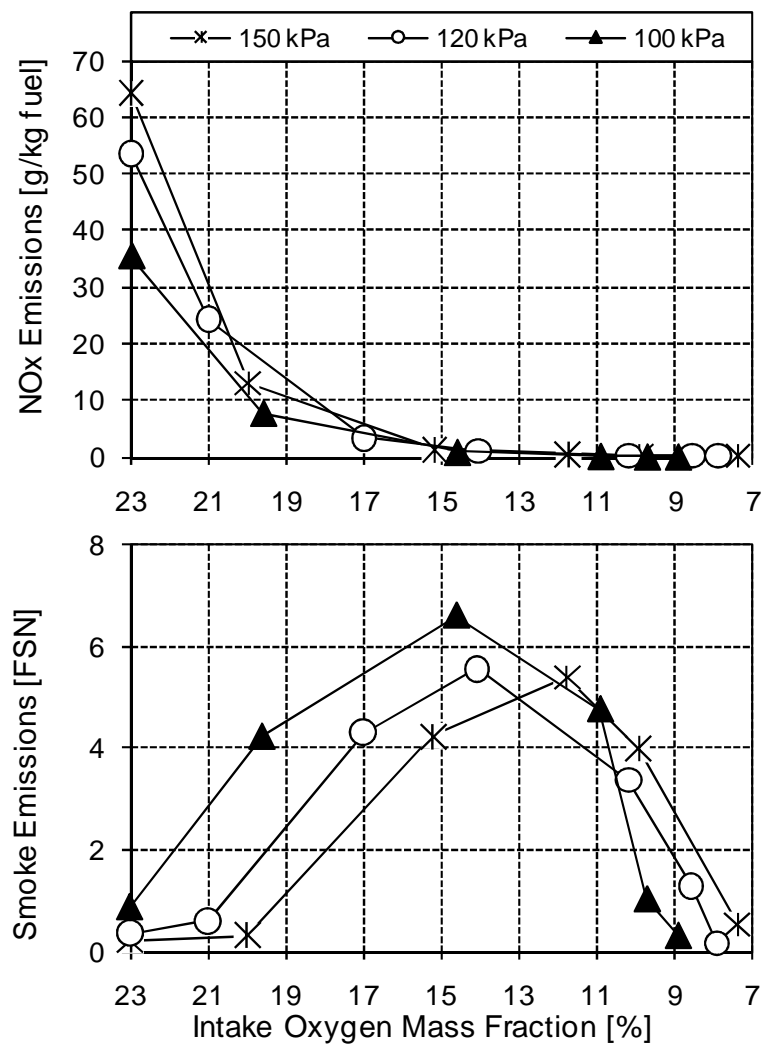

Fig. 5: Variations of $\mathrm{NO}_{\mathrm{X}}$ and smoke emissions with intake oxygen mass fraction at variable intake pressures

The impacts of the transition to LTC modes on THC and CO emissions and fuel consumption (as denoted by the gross indicated specific fuel consumption, GISFC) are shown in Fig. 6 as a function of intake manifold pressure. The findings are generally consistent with previous results at similar operating conditions $[9,10,12,18,19]$. Trends of $\mathrm{CO}$ emissions, shown in Fig. 6, with reduced $\mathrm{YO}_{2}$ are similar to THC emission with the exception that $\mathrm{CO}$ started to show an increasing trend at a higher $\mathrm{YO}_{2}$. It is hypothesised that THC emissions remained constant in the limiting case where engine-out soot was still controlled by soot oxidation rather than soot formation [9]. The reduction in the global equivalence ratio (Figure 3) and improved mixing with higher boost pressures resulted in lower THC and $\mathrm{CO}$ 
emissions under dilute conditions. THC emissions at $150 \mathrm{kPa}$ boost pressure reduced by approximately 97\% and 74\% compared to the $100 \mathrm{kPa}$ and $120 \mathrm{kPa}$ boost pressure cases, respectively. Similarly, at 150 $\mathrm{kPa}$ intake pressure, there was a reduction of CO by approximately $150 \%$ and $111 \%$ compared to the 100 $\mathrm{kPa}$ and $120 \mathrm{kPa}$ intake pressure cases, respectively. This is attributable to the larger amounts of oxygen present late in the combustion event, enabling oxidation of partial combustion products which again elucidates the role of in-cylinder oxygen concentrations on these emissions. This is consistent with an earlier publication [28] in which it was reported that oxygen concentration in the intake charge is the decisive parameter in the high-EGR LTC strategy and the THC and CO emissions show significant sensitivity to a minor change in the EGR rate at the intermediate load LTC operation.

The improvement in the combustion efficiency (due to the improvement in the conversion efficiency of the partial combustion by-products, i.e., THC and CO) also led to significantly lower GISFCs, especially at the highest dilution levels. At high charge dilution (low intake oxygen concentration), the addition of excess air (by increasing the intake pressure) is reported to improve the thermal efficiency primarily by the increased specific heat ratio [31], reduced in-cylinder bulk gas temperature and heat transfer [32]. Increased boost pressure also resulted in lower GISFC in high $\mathrm{YO}_{2}$ conventional diesel combustion. This is attributed to a larger reduction in cooling losses compared to the increase in the exhaust losses at higher boost pressures [33]. Note that the individual contribution of each of the above parameters to the improvement of thermal efficiency were not evaluated in this work. At comparable conditions with simultaneous low-soot and low-NOx emissions, the $150 \mathrm{kPa}$ boost pressure condition achieved a $15 \%$ reduction in GISFC compared to the $100 \mathrm{kPa}$ case. This demonstrates how increased boost under LTC strategies can help to reduce the engine performance penalties. It should be noted that GISFC excludes pumping work, and hence the impacts of turbocharger matching/sizing are not considered here. 

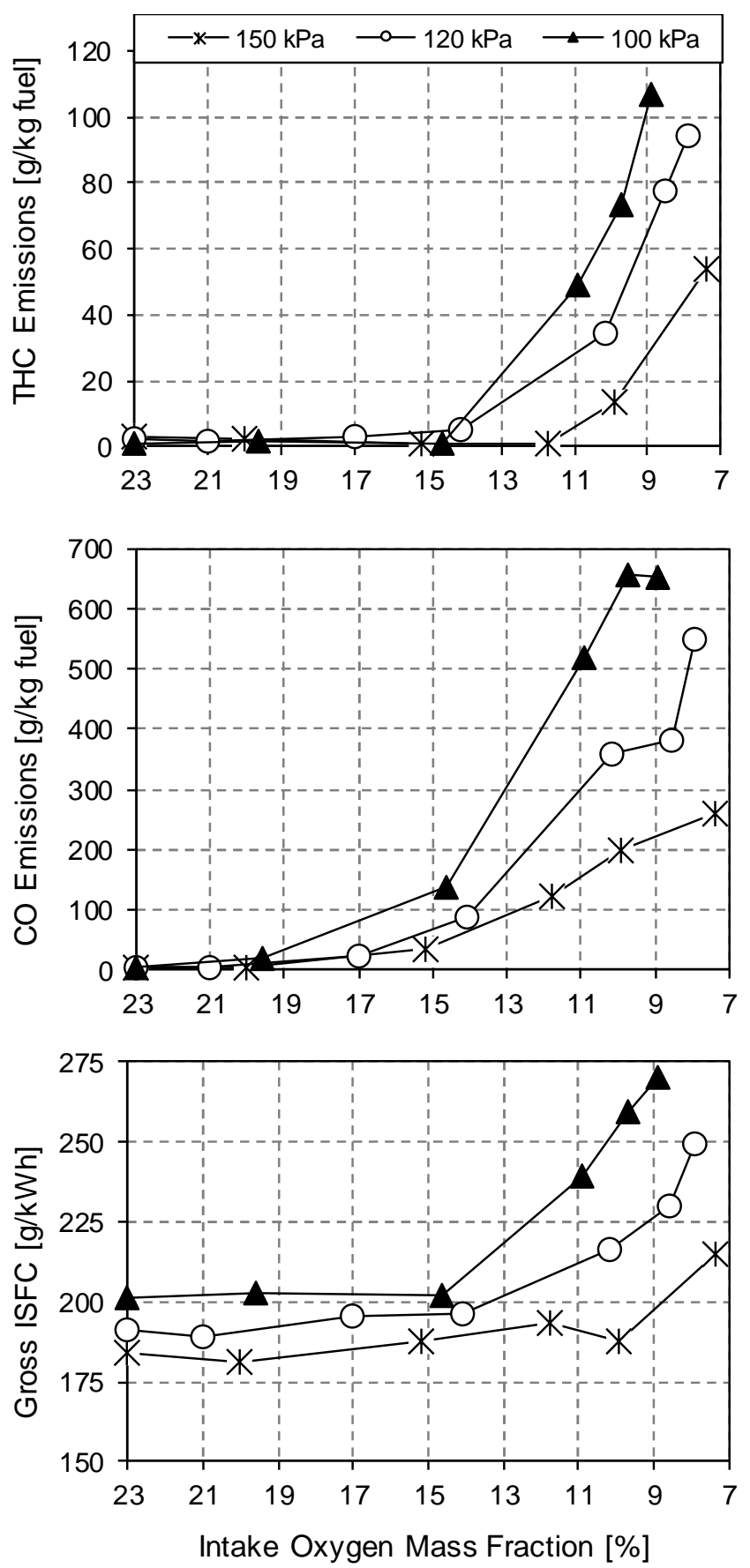

Fig. 6: Variations of THC, $\mathrm{CO}$ emissions and GISFC with intake oxygen mass fraction at variable intake pressures

The EGR sweep results demonstrate the engine operation with low-NOx, low-soot emissions, conditions indicative of highly-dilute LTC behaviour. Higher boost pressure reduced both the higher fuel consumption and increased $\mathrm{CO}$ and THC emissions typically seen at this operating mode, without increasing NOx or tailpipe FSN. For the same engine at an identical operating condition, optical 
assessment of the combustion process can be used to better understand the effects of boost pressure under these highly-dilute LTC modes.

\subsection{Assessment of low smoke, low NOx, high-EGR operating condition}

The highest dilution conditions achieved in the EGR sweep tests were evaluated in more detail using both thermodynamic and optical measurements. Table 4 provides a summary of the operating conditions at high dilution for the three intake manifold pressures tested, and at a comparable conventional diesel combustion (CDC) mode. While all three LTC conditions exhibit low NOx and low FSN, the lowest boost case, with its overall rich equivalence ratio, demonstrates significantly degraded thermal efficiency.

Table 4: Summary of test conditions used in optical assessment

\begin{tabular}{|c|c|c|c|c|}
\hline Boost pressure $(\mathrm{kPa})$ & 100 (LTC) & 120 (LTC) & 150 (LTC) & $120(\mathrm{CDC})$ \\
\hline Intake manifold temperature $\left({ }^{\circ} \mathrm{C}\right)$ & 51 & 50 & 56 & 51 \\
\hline $\mathrm{YO}_{2}(-)$ & 8.9 & 8.2 & 7.4 & 22.8 \\
\hline $\begin{array}{l}\text { Oxygen }\left(\mathrm{O}_{2}\right) \text { based equivalence } \\
\text { ratio (-) }\end{array}$ & 1.02 & 0.98 & 0.89 & 0.45 \\
\hline EGR (\% by volume) & 56.5 & 59.0 & 63.6 & 4.0 \\
\hline Fuelling mass (mg/cycle) & 16 & 16 & 16 & 16 \\
\hline GIMEP (bar) & 4.6 & 5.0 & 5.4 & 6.4 \\
\hline $\begin{array}{l}\text { Coefficient of variation (COV) } \\
\text { GIMEP }(\%)\end{array}$ & 2.26 & 1.43 & 1.77 & 1.53 \\
\hline SOI $\left({ }^{\circ} \mathrm{CA}\right.$ ATDC $)$ & -30 & -30 & -30 & $\begin{array}{l}-6 \text { (Main) } \\
-24 \text { (Pilot) }\end{array}$ \\
\hline Ignition delay $\left({ }^{\circ} \mathrm{CA}\right)$ & 25.5 & 24.5 & 21 & 1.5 \\
\hline CA50 ( ${ }^{\circ} \mathrm{CA}$ ATDC $)$ & 10 & 3.5 & 0.5 & 3.5 \\
\hline Standard deviation CA50 $\left({ }^{\circ} \mathrm{CA}\right)$ & 0.93 & 0.38 & 0.21 & 0.13 \\
\hline CA10-CA90 $\left({ }^{\circ} \mathrm{CA}\right)$ & 17 & 17 & 23.5 & 25.5 \\
\hline Indicated specific NOx $\left(\mathrm{g} / \mathrm{kWh}_{\mathrm{i}}\right)$ & 0.031 & 0.033 & 0.034 & 9.394 \\
\hline Smoke (FSN) & 0.18 & 0.17 & 0.10 & 0.26 \\
\hline GISFC (g/kWh) & 240.0 & 221.0 & 203.0 & 175.6 \\
\hline Exhaust $\mathrm{O}_{2}(\%$ by volume $)$ & 1.8 & 2.1 & 2.8 & 11.95 \\
\hline Exhaust port temperature $\left({ }^{\circ} \mathrm{C}\right)$ & 246 & 238 & 253 & 320 \\
\hline
\end{tabular}

The long ignition delay with high dilution results in highly premixed combustion for all three intake manifold pressures. The energy release rates calculated from the in-cylinder pressure are shown in Figure 7a (Figure 7b, the FOV integrated net luminosity, is discussed later). The energy release rates in Figure 7 demonstrate a negative temperature coefficient (NTC) regime [34] prior to the onset of the main combustion phase. The NTC phase occurs slightly earlier with higher boost pressures. It is also of shorter duration, leading to a more advanced main (high temperature) energy release. At all three 
pressures, the main combustion phase shows a nearly-symmetric shape, indicative of a high degree of premixing; this would be expected given the long ignition delay and low total fuelling quantity. The highest intake pressure does show a slightly more skewed energy release (faster early energy release, but slower later) indicative of some more stratification in the mixture, likely due to the shorter ignition delay at the higher boost pressure. The late combustion phases for all three boost pressures show very little activity after about $30^{\circ} \mathrm{CA}$ ATDC. Given the high concentrations of CO and THC that will still be present in the combustion chamber, this suggests that local temperatures have dropped below the level that could sustain reactions. At the lowest boost pressure, there may also be a lack of available oxygen due to the overall rich mixture; however, given that $1.8 \% \mathrm{O}_{2}$ (by volume) was measured in the exhaust, it appears that the reactions have stopped before all the $\mathrm{O}_{2}$ could be consumed.
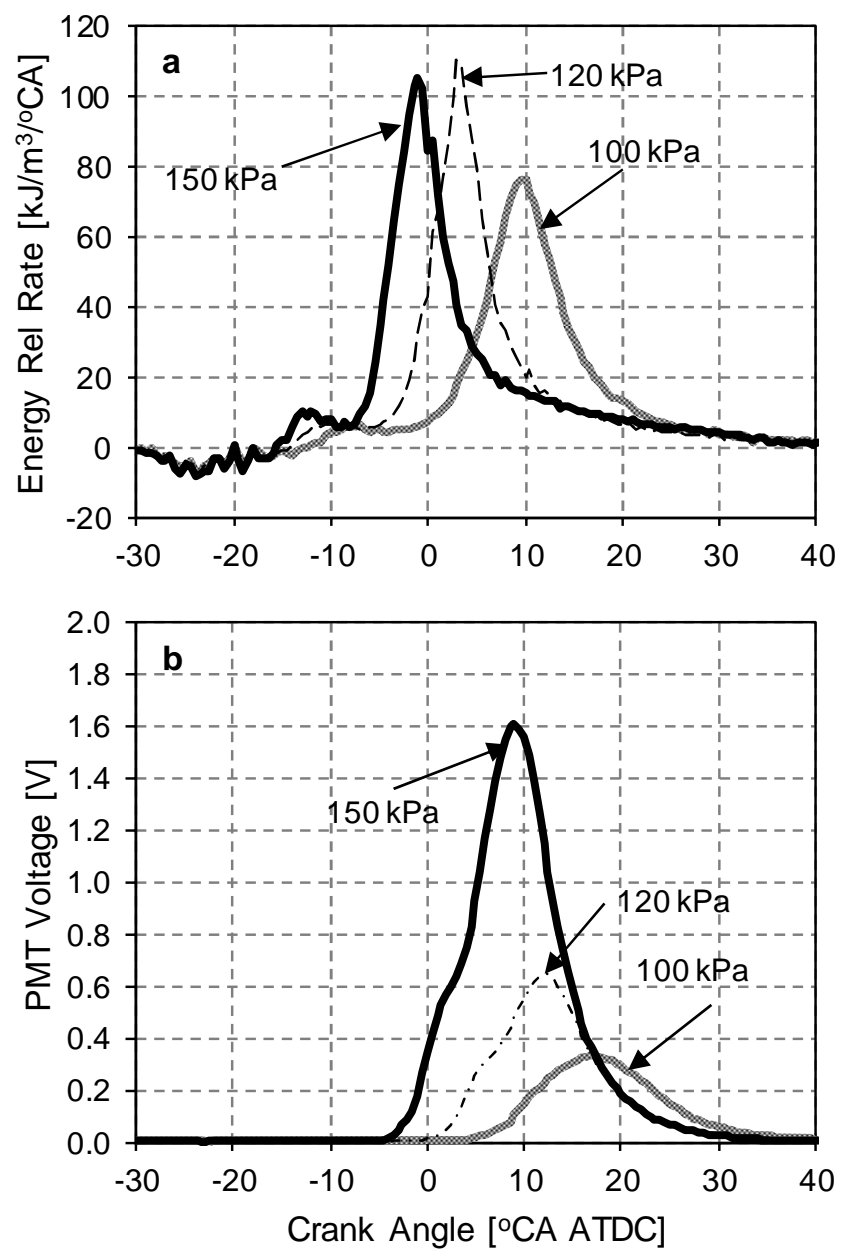

Fig. 7: a) Energy release rate and b) PMT signal at three intake pressures for high-EGR LTC conditions $-63.6 \% \mathrm{EGR}\left(\mathrm{YO}_{2} \sim 7.4 \%\right)$ at $150 \mathrm{kPa} ; 59 \% \mathrm{EGR}\left(\mathrm{YO}_{2} \sim 8.2 \%\right)$ at $120 \mathrm{kPa}$; and $56.5 \% \mathrm{EGR}\left(\mathrm{YO}_{2} \sim 8.9 \%\right)$ at $100 \mathrm{kPa}$ 
To gain further insight into the combustion event, a sequence of spray and flame images for the high-EGR LTC at 120 and $150 \mathrm{kPa}$ can be compared. It should be noted that the relatively low framerate of the camera meant that the individual frames are taken from separate cycles. However, combustion variability was low even at LTC, as shown in Table 4; so the impact of cycle-to-cycle variability is expected to be small. The combustion images for the high-EGR LTC cases at 120 and $150 \mathrm{kPa}$ boost pressure differ significantly, as shown in Fig. 8. This is particularly significant given that the shapes of the energy release profiles are similar, aside from a $5^{\circ} \mathrm{CA}$ shift in phasing in the peak energy release rate for the lower boost pressure case (refer to Fig. 7a). In both cases, the fuel spray (Fig. 8a) appears at -28 ${ }^{\circ} \mathrm{CA}$ ATDC and continues for $6{ }^{\circ} \mathrm{CA}$, with injection clearly completed by $-23^{\circ} \mathrm{CA}$ ATDC. This suggests the injection duration was approximately $0.67 \mathrm{~ms}$, with an injector opening delay (commanded-actual SOI) of $0.17 \mathrm{~ms}$. The images clearly show the sprays penetrating through the field-of-view. This suggests that they will have impinged on the piston bowl wall by - $26{ }^{\circ} \mathrm{CA}$ ATDC; this is supported by spray penetration calculations [22]. The images clearly indicate little difference in the injection event between the different boost pressures evaluated. It was hypothesised by Han et al. [10] that at higher intake pressure (higher ambient density) liquid penetration inside the cylinder during the injection event had a shorter penetration distance, leading to a lower probability of wall impingement and hence a reduction of THC emissions. This hypothesis could not be verified from the spray imaging and spray penetration calculation in the present work.

No natural luminosity from combustion were observed during the pre-combustion and NTC regimes for both boost pressures (shown in Figure 8b). This phase of the combustion event is defined based on the energy release plots (Fig. 7a), from the EOI to the inflection point at the start of the main (high temperature) energy release $\left(-8{ }^{\circ} \mathrm{CA}\right.$ ATDC for $150 \mathrm{kPa},-6{ }^{\circ} \mathrm{CA}$ ATDC for $120 \mathrm{kPa}$ case). The frames in Fig. $8 \mathrm{~b}$ start at $-11^{\circ} \mathrm{CA}$ ATDC since no significant effects were observed between EOI and this point. Reactions leading to natural chemiluminescence could have been occurring; however, the limited spectral ranges of the optical components (borescope and camera) and gain of the camera (30 $\mathrm{dB}$ ) would have required very high emission intensities to be detected.

The initial main phase of the combustion is defined as the duration from the apparent start of high temperature energy release to the peak energy release rate. This phase again shows no distinct flame structure for either boost pressure, as shown in Figure 8b. The lack of flame luminosity in these images is unsurprising; previous research $[4,8,10,12]$ had shown that soot formation in diesel engines is 
inhibited by very high levels of EGR owing to low local in-cylinder temperature and long ignition delay leading to high degrees of premixing. Some 'clouding' in the bowl indicates some luminous combustion occurring at the $150 \mathrm{kPa}$ case at the end of this combustion phase; no clear light emissions are evident for the $120 \mathrm{kPa}$ image.

The later stage of the main combustion event shows more significant differences between the 120 and $150 \mathrm{kPa}$ LTC cases. This phase is from the peak energy release rate to the significant reduction in energy release apparent in the energy release plots $\left(120 \mathrm{kPa}: 4^{\circ} \mathrm{CA}-10{ }^{\circ} \mathrm{CA} \mathrm{ATDC} ; 150 \mathrm{kPa}: 0^{\circ} \mathrm{CA}-\right.$ $7{ }^{\circ} \mathrm{CA}$ ATDC). The borescope images for this phase are shown in Figure $8 \mathrm{c}$ for both pressures. Due to the significant change in combustion phasing between the two intake pressures, the selected frames are from different crank angles, but they are sequenced so that the corresponding CAs are aligned in the figure. At $120 \mathrm{kPa}$, there is some indication of distinct flame luminosity appearing in the piston bowl especially around $10{ }^{\circ} \mathrm{CA}$ ATDC. A much more distinct flame can be seen during this phase in the 150 $\mathrm{kPa}$ case. Light emissions from the whole of the visible region of the piston bowl are apparent, with varying intensity, through the entire sequence. This very distinct difference is particularly intriguing given the relative similarity of the energy release plots, NOx emissions, and tailpipe FSN levels.

The post-combustion phase, which represents the 'tail' of the combustion event, is shown in Figure 8d. This sequence of images represents low energy-release rates with oxidation of combustion by-products limited by mixing between the burned gas zones with remaining oxygen in the cylinder. As such, it is sensitive to both temperatures and turbulence levels, both of which decay as the cylinder volume increases during the expansion stroke. It is interesting to note that the luminous intensity at 10 ${ }^{\circ} \mathrm{CA}$ ATDC at $120 \mathrm{kPa}$ intake pressure (Fig. 8c) roughly coincides with the luminosity at $17{ }^{\circ} \mathrm{CA}$ ATDC at $150 \mathrm{kPa}$ intake pressure (Fig. 8d). Again, the high-EGR LTC at higher intake pressure was characterised by longer flame luminosity duration $\left(15^{\circ} \mathrm{CA}\right.$, between 2 and $17^{\circ} \mathrm{CA}$ ATDC) compared to $120 \mathrm{kPa}$ intake pressure. This reinforces the earlier observation of longer combustion duration (Table 4) with high intake pressure in the high-EGR LTC strategy, which is consistent with previous publications $[10,19]$. This supports the hypothesis that bulk quenching of the mixture has been delayed at higher intake pressure as a result of the advanced combustion phasing, expected higher local flame temperature and higher in-cylinder oxygen concentration [19]. 


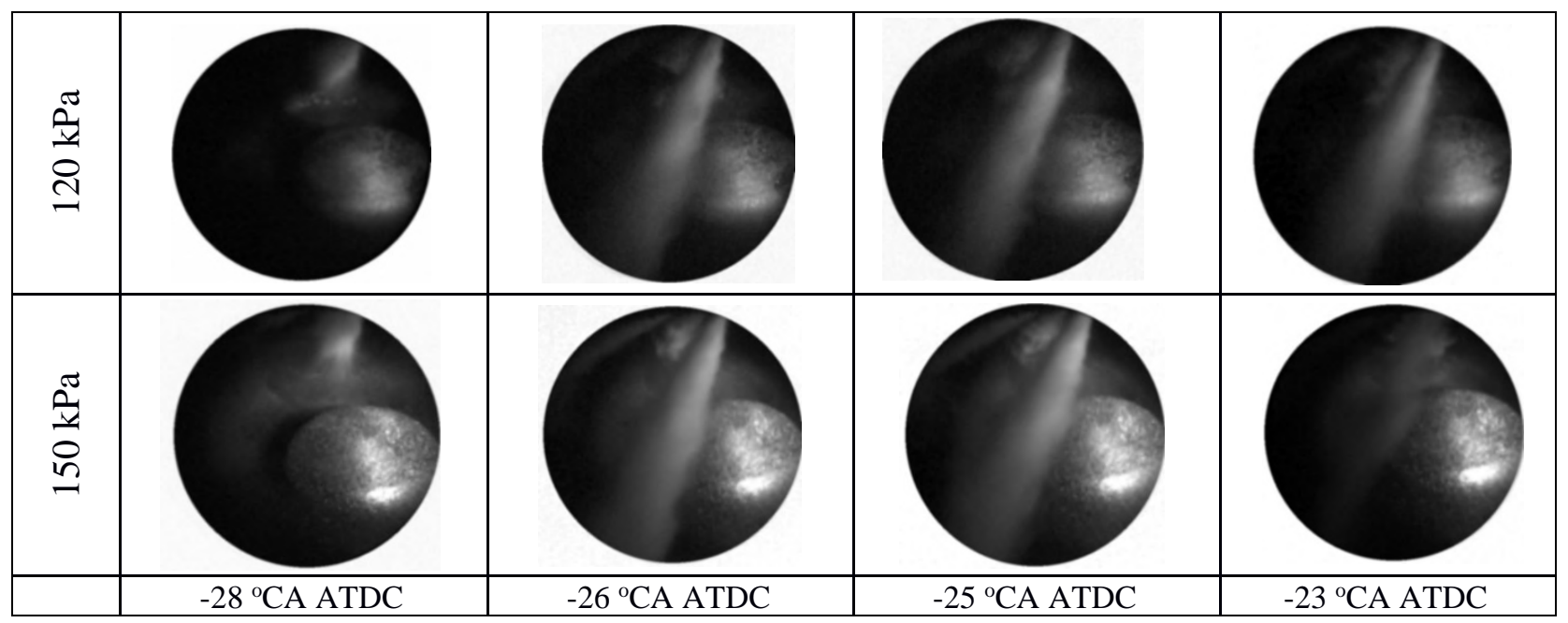

(a) Spray images at $120 \mathrm{kPa}$ (top row) and $150 \mathrm{kPa}$ (bottom row) intake pressures in high-EGR LTC

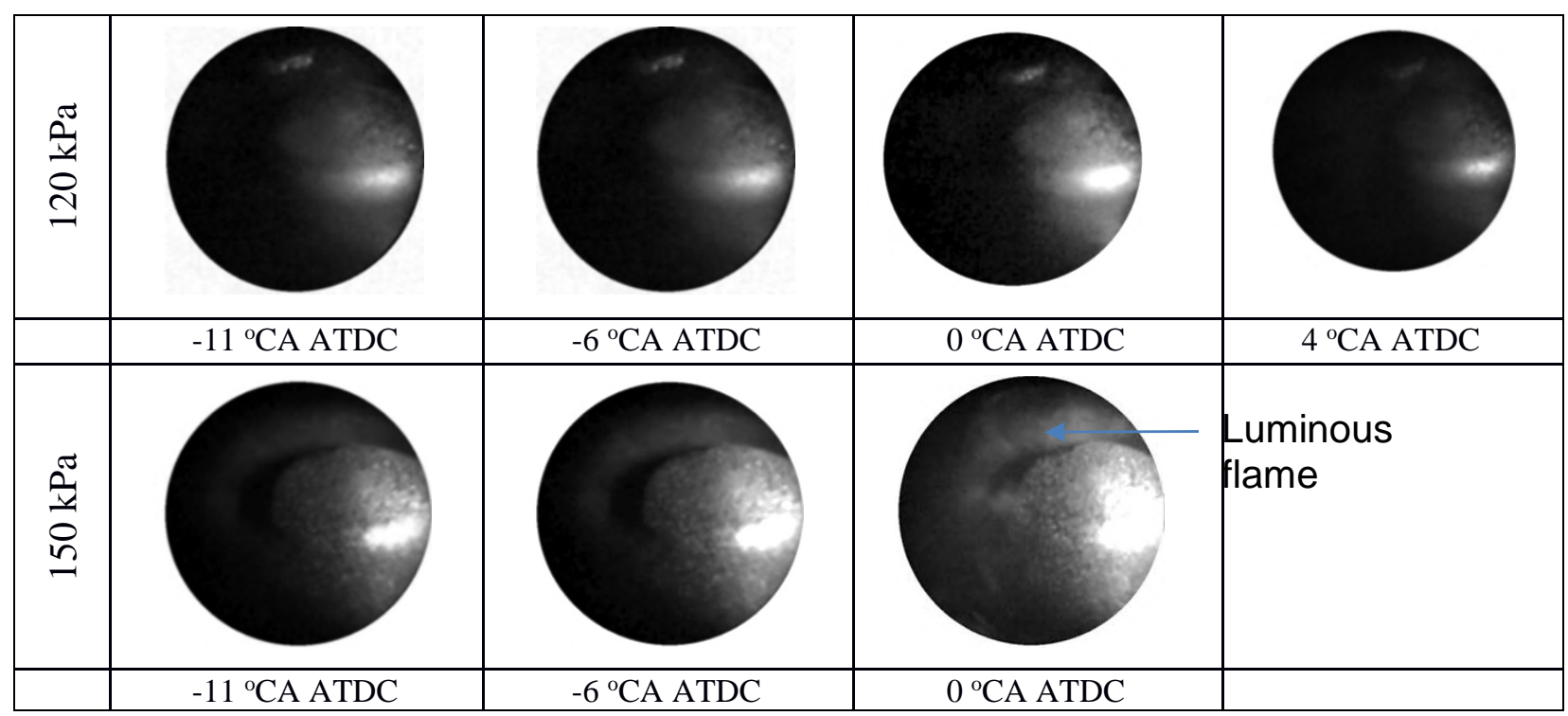

(b) Pre-combustion, NTC and the initial stage of main combustion phases of energy release at $120 \mathrm{kPa}$ (top row) and $150 \mathrm{kPa}$ (bottom row) intake pressures in high-EGR LTC

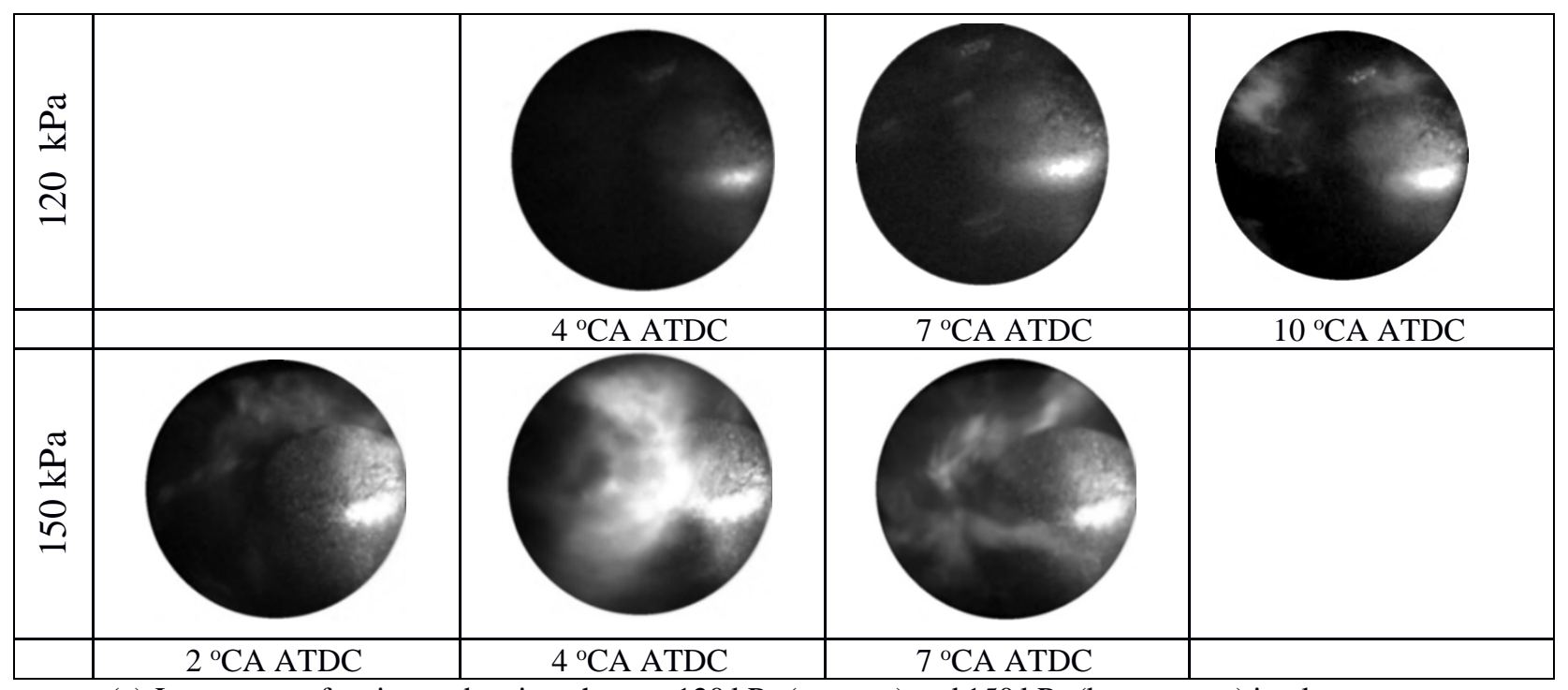

(c) Later stage of main combustion phase at $120 \mathrm{kPa}$ (top row) and $150 \mathrm{kPa}$ (bottom row) intake pressures in high-EGR LTC operation at selected instances 


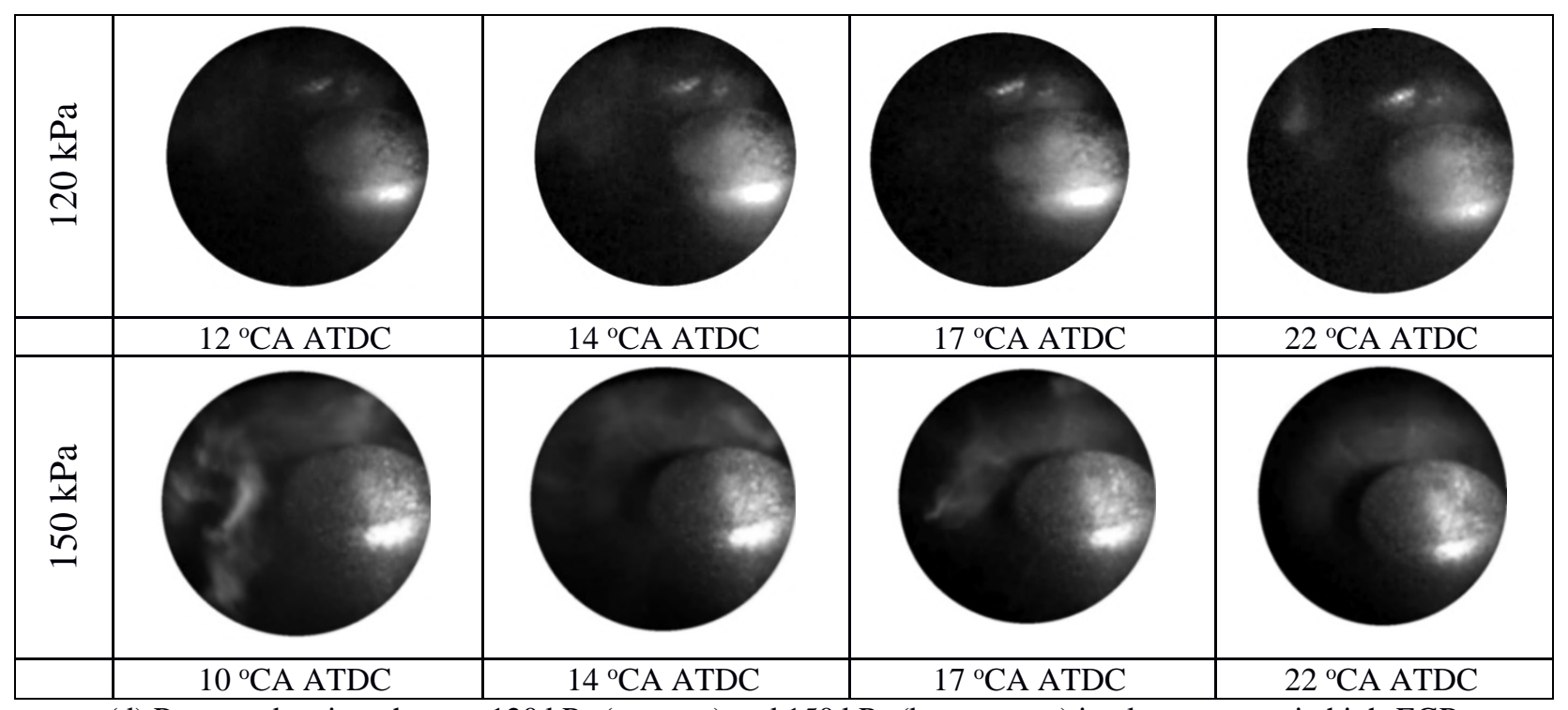

(d) Post combustion phase at $120 \mathrm{kPa}$ (top row) and $150 \mathrm{kPa}$ (bottom row) intake pressures in high-EGR LTC

Fig. 8: Comparison of spray and flame images between 120 and $150 \mathrm{kPa}$ intake pressures in high-EGR LTC (camera gain $30 \mathrm{~dB}$ )

Comparing the natural luminosity borescope images with the field-of-view integrated soot incandescence, shown in Figure 7b, is insightful. The camera and PMT used the same borescope, resulting in equivalent fields-of-view. The soot luminosity, corresponding to $120 \mathrm{kPa}$ intake pressure LTC case, started to appear close to TDC and peaked at $\sim 10{ }^{\circ} \mathrm{CA}$ ATDC and continued until $30^{\circ} \mathrm{CA}$ ATDC. These results indicate that there was measurable soot present in the cylinder during the highEGR LTC operation that was not visible in the combustion images (Fig. 8). Note that during LTC operation, the control voltage of the PMT was set at $0.65 \mathrm{~V}$ which corresponds to a PMT gain of $\sim 10^{5}$ [25]. At $150 \mathrm{kPa}$ intake pressure, soot luminosity started to appear at $-3{ }^{\circ} \mathrm{CA}$ ATDC, coinciding with the initial stage of main combustion phase (Fig. 8b). Soot luminosity appeared at TDC and at $2{ }^{\circ} \mathrm{CA}$ ATDC for $120 \mathrm{kPa}$ and $100 \mathrm{kPa}$ boost pressure cases respectively. It is expected that the shorter ignition delay and the advanced combustion phasing, shown in Fig. 4, at high intake pressure resulted in the earlier soot luminosity. At lower intake pressures, the peak soot luminosity was significantly later $\left(\sim 8^{\circ} \mathrm{CA}\right.$ at 100 $\mathrm{kPa}$ compared to $150 \mathrm{kPa}$ boost pressure) in the cycle and coincided with the beginning of the post combustion phase (shown in Fig. 8d). This is consistent with other work [4, 8], which reported that the initial natural incandescence of soot coincided with the beginning of the premixed energy release phase of combustion. In the high-EGR LTC strategy reported here, the peak soot luminosities were 
substantially higher ( five times) for the $150 \mathrm{kPa}$ intake pressure case (Fig. $7 \mathrm{~b}$ ) compared to the naturally aspirated LTC condition.

At the higher boost pressures, soot incandescence decreased rapidly from its peak values. This rapid reduction after $17^{\circ} \mathrm{CA}$ for $150 \mathrm{kPa}$ and $120 \mathrm{kPa}$ intake pressure was likely due to the rapid oxidation of soot at higher boost pressure and at higher in-cylinder temperature. At low intake pressure, soot was radiating but the lack of available oxygen means that little oxidation occurred later in the expansion stroke. The radiation eventually decreased due to the dropping bulk temperatures during the expansion stroke. This study hints at the complex trade-off between soot formation (not evaluated here) and soot oxidation rate (visually observed) at different intake pressures caused by variation in ignition delay, local fuel-oxygen ratio and local flame temperature. The trend of flame luminosity observed in this work is different from the findings of Han et al. [10] where the soot luminosity in LTC decreased at higher intake pressure at a fixed intake oxygen concentration $(11.25 \%$ by volume). Note that in the present work higher levels of EGR was required to achieve low smoke emissions in the high boost pressure LTC cases, which is consistent with other work $[18,19]$. The trend in the flame luminosity is expected to be strongly dependent on intake charge dilution, since engine-out smoke emissions show significant sensitivity to the minor changes in the EGR rate at the intermediate load (16 mg/cycle fuelling quantity) LTC operating condition [28]. Therefore, the increased EGR levels at high intake pressure, as is the case in the present investigation, would impact the soot luminosity and its distribution inside the combustion chamber significantly. However, a sensitivity analysis, involving optical studies, was beyond the scope of this work.

\subsection{Comparison between LTC and conventional diesel combustion}

It is also interesting to compare high-EGR LTC combustion images with those of an equivalent CDC case. Selected images are shown in Fig. 9, for the $150 \mathrm{kPa}$ high-EGR LTC case compared to the $120 \mathrm{kPa}$ boost CDC. Although engine-out soot emissions (FSN) in CDC was very similar to that of highEGR LTC (Table 4), the combustion images are markedly different. In the case of conventional diesel operation, a small pilot injection $(1.5 \mathrm{mg} /$ stroke $)$ at $-24{ }^{\circ} \mathrm{CA}$ ATDC was used to control the rate of pressure rise within the cylinder. No flame luminosity was observed for the pilot combustion, likely due to the limited gain and spectral range of the camera. In CDC, the main fuel injection started at $-6{ }^{\circ} \mathrm{CA}$ ATDC and continued until $-2{ }^{\circ} \mathrm{CA}$ ATDC. Combustion for the main fuel started almost immediately, 
while the fuel was still being injected. This could be due to the presence of the flammable pilot mixture near the plume of the main jet. Similar flame luminosity, at the start of the main fuel injection event, was also reported in an earlier publication [35]. As the borescope images demonstrate, ignition sites are seen almost immediately after the start of injection, with significant luminous combustion occurring while the injection proceeds. This will have increased soot formation although most of it will have been oxidised at the high flame temperatures of CDC [2]. This high-temperature oxidation results in much stronger broadband light emissions, as shown in Fig. 9.

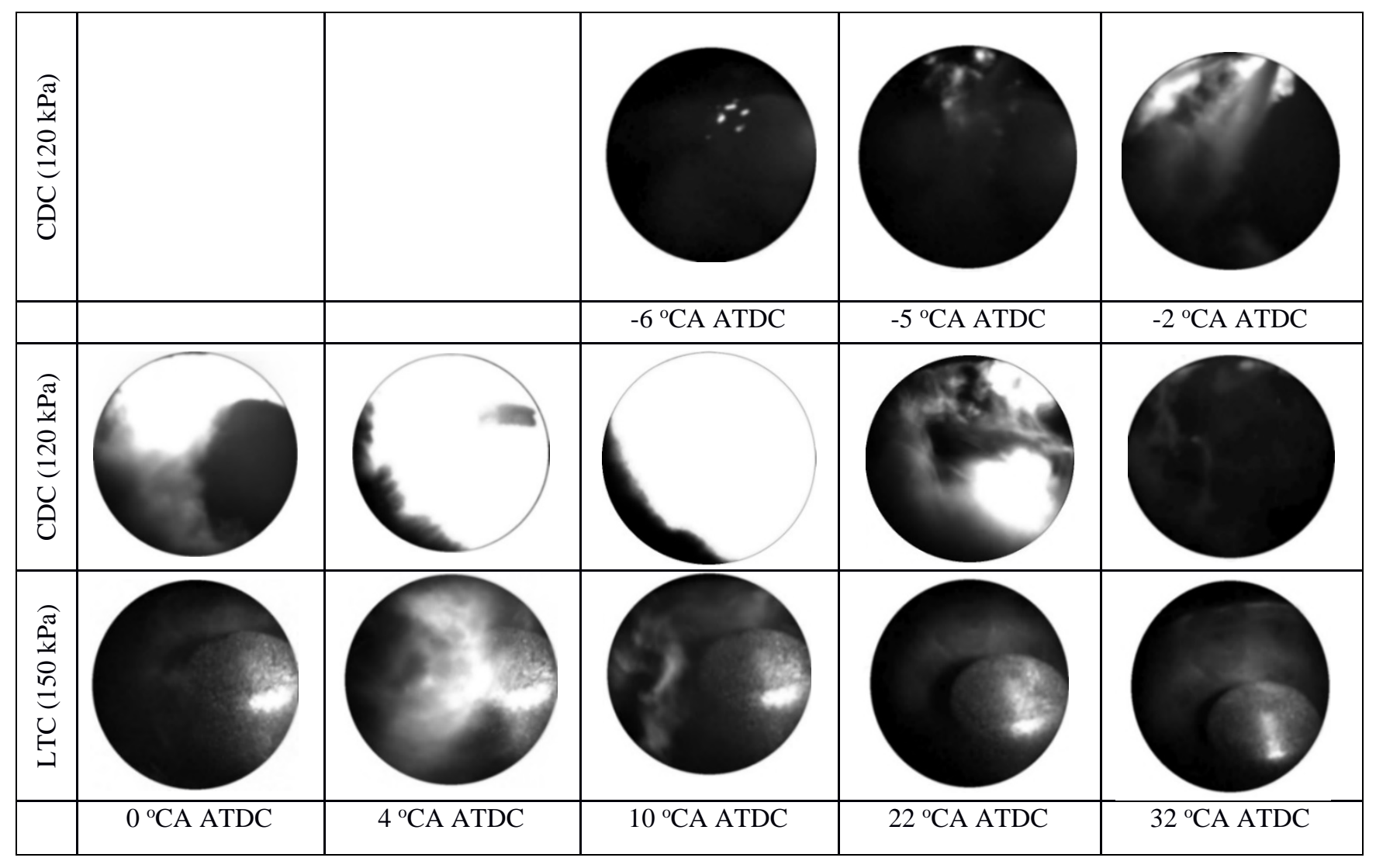

Fig. 9: Comparison of in-cylinder natural luminosity at $120 \mathrm{kPa}$ intake pressure CDC (20 dB camera gain) and $150 \mathrm{kPa}$ intake pressures in high-EGR LTC (30 dB camera gain) at selected instances

Unlike the high-EGR LTC case, the main combustion event in the conventional diesel operation is characterised by high levels of flame luminosity that fill a significant fraction of the borescope FOV over a period of approximately $22{ }^{\circ} \mathrm{CA}$, from $0{ }^{\circ} \mathrm{CA}$ ATDC to $22{ }^{\circ} \mathrm{CA}$ ATDC. Luminous combustion continued up to $32{ }^{\circ} \mathrm{CA}$ ATDC in CDC, whereas in LTC, despite a higher camera gain, no luminous flame could be seen after $10{ }^{\circ} \mathrm{CA}$ ATDC. Note that in CDC, soot incandescence is several orders of magnitude stronger than chemiluminescence [12]. It is also interesting to note that the soot cloud late in 
the combustion phase in the conventional diesel case was widely distributed in the piston bowl compared to the narrow local luminosity seen in the high-EGR LTC case. This suggests a lesser degree of nonhomogeneity in the air-fuel charge mixture in high-EGR LTC operation compared to CDC. This is similar to the direct in-cylinder flame imaging results reported by Han et al. [10]. In the cited work a high luminous intensity diffusion flame was observed at the periphery of the spray jet with conventional diesel combustion, while no diesel jet-shaped flame structure was observed in the LTC regime and the flame luminosity was evenly distributed inside the piston bowl. It should be noted that although the flame luminosity in CDC is primarily dominated by bright soot incandescence, which is a function of both high flame temperature and soot concentration [2], it does not necessarily mean a higher engine-out soot emission. This is evident from the engine-out smoke emission data, shown in Table 4.

Comparing the soot luminosity with the energy release rate for conventional diesel combustion, shown in Fig. 10, it can be seen that the soot luminosity appeared at $-3{ }^{\circ} \mathrm{CA}$ ATDC, for both CDC and LTC. That coincides with the onset of the high temperature energy release phase, after the low temperature energy release from the pilot fuel in CDC and pre-combustion and NTC phases in LTC. The pilot combustion and the early phase of the main combustion events were not captured in the PMT data due to low gain $(\sim 500)$ to avoid saturating the sensor during the main combustion phase. Note that the gain setting in LTC was corrected against the PMT gain in CDC; therefore, the PMT voltages are directly comparable. The peak soot luminosity in CDC occurred at $\sim 9^{\circ} \mathrm{CA}$ ATDC, coinciding with the later stage of main combustion phase (high temperature mixing-control energy release). The energy release rate profiles look similar for both CDC and LTC, although there is approximately three order of difference in magnitude in the PMT output. The duration of the luminosity (attributed to soot oxidation) extends about $10{ }^{\circ} \mathrm{CA}$ ATDC later in CDC than in LTC. This reinforces the importance of the dropping incylinder temperatures, and the corresponding bulk quenching of the reactions, on the late-phase combustion in high-EGR LTC. As this phase would be expected to complete the conversion of partialcombustion by-products to $\mathrm{CO}_{2}$ and $\mathrm{H}_{2} \mathrm{O}$, it likely directly influences the high $\mathrm{THC}$ and $\mathrm{CO}$ emissions, and corresponding drop in combustion efficiency, for the LTC conditions. 

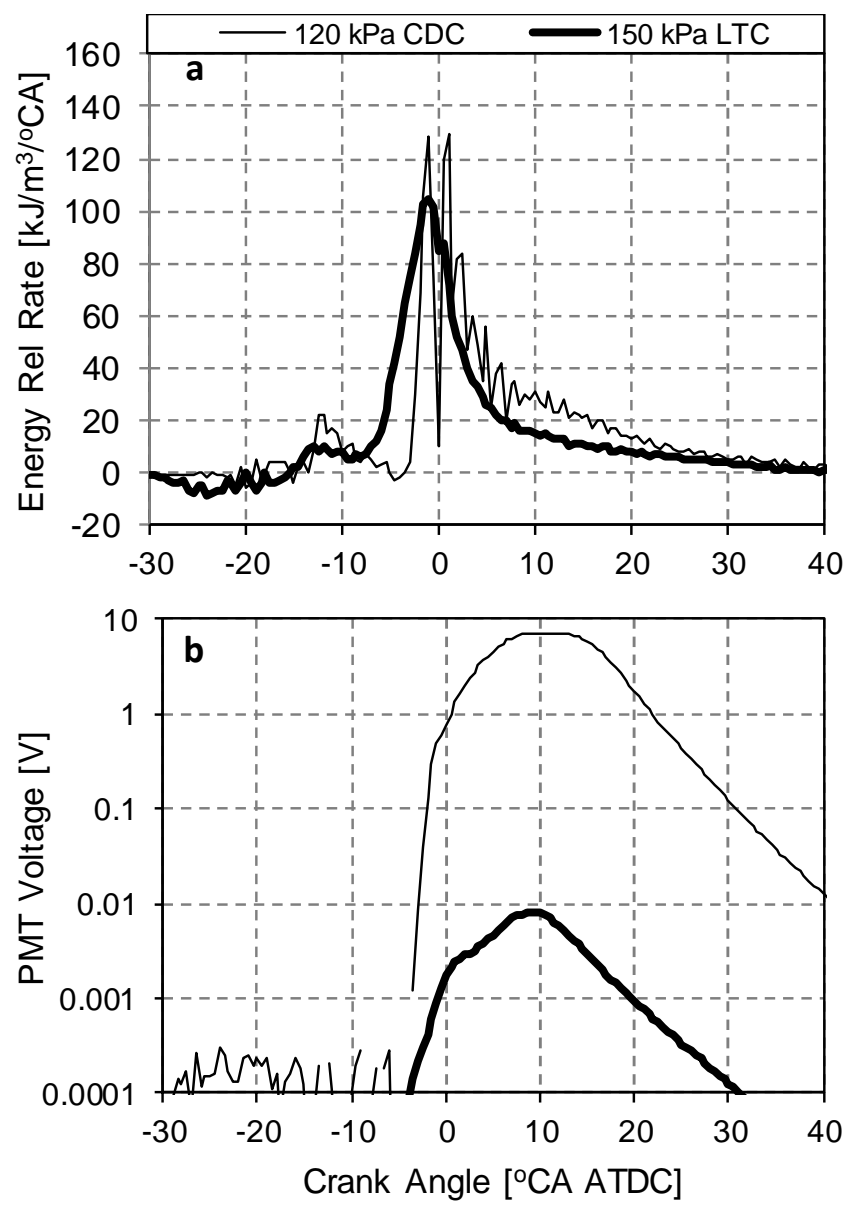

Fig. 10: a) Energy release rate and b) normalised PMT signal in conventional diesel combustion $\left(\mathrm{YO}_{2}\right.$ $\sim 23 \%)$ and high-EGR LTC $\left(\mathrm{YO}_{2} \sim 7.4 \%\right)$

When considering the suitability of high-dilution, low-temperature combustion compared to $\mathrm{CDC}$, it is important to evaluate the effects of the combustion event on both engine-out emissions and on the likely effectiveness of an exhaust after-treatment system (EATS). While a detailed assessment of the EATS performance is outside of the work reported here, engine-out exhaust temperature and emissions levels (Table 4) provide some important insights. For the $\sim 6$ bar GIMEP condition tested, the engine out exhaust temperature for conventional diesel combustion was $320^{\circ} \mathrm{C}$. Considering the temperature drop through the turbocharger turbine and exhaust system, this low temperature will result in sub-optimal selective catalytic reduction (SCR) performance, especially during transient operation. This will likely result in cycle-composite tailpipe NOx emissions that exceed future stringent NOx emissions. The very low engine-out NOx emissions realized through high dilution low-temperature combustion at the tested and lower loads offers an in-cylinder control strategy that can reliably achieve ultra-low NOx levels without depending on after-treatment system performance. Further, these low NOx 
emissions are relatively insensitive to dilution or boost conditions, as shown in Figure 5. These results suggest that high dilution LTC with boost control offers a viable and robust approach to achieving low tailpipe NOx emissions under conditions where conventional after-treatment systems would not be effective.

\section{Conclusions}

The effects of intake manifold pressures on combustion, emissions and performance under highEGR low temperature combustion were evaluated using a combination of thermodynamic and optical (imaging and field of view integrated) approaches. This work provides a direct comparison between optically-observed combustion progression and resulting thermodynamic performance and emissions at high-dilution low temperature combustion. Unlike in previous studies, the optical and thermodynamic studies were conducted with an identical engine geometry with a representative piston bowl and using actual recirculated exhaust gases to provide charge dilution. This removes several important sources of uncertainty in the comparison of the experimental results. Good correlations were established between soot luminosity, energy release rate and unfiltered combustion images both under high-EGR low temperature combustion conditions and conventional diesel combustion regimes.

Increasing intake pressure in the high-EGR low temperature combustion regime was found to:

- increase the intensity of the soot luminosity and the duration over which soot luminosity was visible within the cycle

- advance the timing of the first observed soot luminosity within the cycle and also the timing of peak soot luminosity

- increase the rate at which the soot luminosity decayed from its peak value

- increase the intensity, duration and area of natural combustion (flame) luminosity within the piston bowl

- reduce gross indicated specific fuel consumption and unburned total hydrocarbons and carbon monoxide emissions without having an impact on NOx emission.

Increasing the intake pressure in the high-EGR low temperature combustion regime contributes to reduction of unburned total hydrocarbons and carbon monoxide emissions, and the consequent reduction of gross indicated specific fuel consumption, by increasing oxygen availability and sustaining combustion reactions further into the expansion stroke. This provides evidence that, through the combination of appropriate boost pressures and EGR rates, the onset of bulk quenching can be delayed, 
reducing the emissions and thermal efficiency penalty of near-zero NOx ( $<10 \mathrm{ppm}, \sim 0.05 \mathrm{~g} / \mathrm{kWh}$ ) operation impacts using the high-dilution EGR approach to achieve low-temperature combustion. This offers further insight into a useful tool that engine developers can use to control NOx emissions under cold-start and off-cycle conditions that are critical to meeting upcoming emissions standards. By minimising NOx and particulate emissions at low and part loads, this combustion approach can contribute to ensuring the ongoing availability of high-efficiency diesel engines for suitable transportation applications.

\section{Acknowledgements}

The authors would like to thank Mr Adrian Broster, Mr Steve Horner, Mr Graham Smith and Mr Steve Taylor at Loughborough University's IC Engines and Powertrain Laboratory for their assistance with the optical set up and engine testing. The authors acknowledge Dr Edward Winward at Loughborough University for his help with the LABVIEW code for image acquisition. The authors acknowledge the financial support from the UK Engineering and Physical Sciences Research Council (EPSRC, Grant F031351/01) and the Royal Academy of Engineering.

\section{References}

[1] Ladommatos, N., Abdelhalim, S., and Zhao, H., 2000, "The effects of exhaust gas recirculation on diesel combustion and emissions”, International Journal of Engine Research, vol. 1, no. 1, pp. 107-126.

[2] Lee, S., Yoon, S., Kwon, H., Lee, J., and Park, S., 2019, "Effects of engine operating conditions on flame propagation processes in a compression ignition optical engine", Applied Energy, vol. 254, 113642 .

[3] Thangaraja, J. and Kannan, C., 2016, "Effect of exhaust gas recirculation on advanced diesel combustion and alternate fuels - a review", Applied Energy, vol. 180, pp. 169-184.

[4] Dec, E.J., 2009, "Advanced compression-ignition engines-understanding the in-cylinder processes", Proceedings of the Combustion Institute, vol. 32, no. 2, pp. 2727-2742.

[5] Saxena, S., and Bedoya, I., 2013, "Fundamental phenomena affecting low temperature combustion and HCCI engines, high load limits and strategies for extending these limits", Progress in Energy and Combustion Science, vol. 39, pp. 457-488.

[6] Sarangi, A.K., Garner, C.P., McTaggart-Cowan, G.P., Davy, M.H, Wahab, E., and Peckham, M., 2013, "The effects of split fuel injections on high exhaust gas recirculation low-temperature diesel engine combustion", International Journal of Engine Research, vol. 14, no. 1, pp. 68-79.

[7] Molina, S., Garcia, A., Monsalve-Serrano, J, and Villalta, D., 2019, "Effects of fuel injection parameters on premixed charge compression ignition combustion and emission characteristics in a medium-duty compression ignition diesel engine", International Journal of Engine Research, Onlinefirst, $1-13$. 
[8] Musculus, M.P.B., Miles, P.C., and Pickett, L.M., 2013, "Conceptual models for partially premixed low-temperature diesel combustion”, Progress in Energy and Combustion Science, vol. 39, pp. 246-283.

[9] Benajes, J., Molina, S., Novella, R., and Belarte, E., 2014, "Evaluation of massive exhaust gas recirculation and Miller cycle strategies for mixing-controlled low temperature combustion in a heavy duty diesel engine", Energy, vol. 71, pp. 355-366.

[10] Han, S., Kim, J., and Bae, C., 2014, "Effect of air-fuel mixing quality on characteristics of conventional and low temperature diesel combustion", Applied Energy, vol. 119, pp. 454-466.

[11] Lee, Y., and Huh, K.Y., 2014, "Analysis of different modes of low temperature combustion by ultrahigh EGR and modulated kinetics in a heavy duty diesel engine", Applied Thermal Engineering, vol. 70, pp. 776-787.

[12] Jung, Y., Park, S.S., and Bae, C., 2015, "Effects of oxygen concentration on highly diluted charge compression ignition combustion in a diesel engine", Applied Thermal Engineering, vol. 90, pp. 538550 .

[13] d'Ambrosio, S. and Ferrari, A., 2015, "Effects of exhaust gas recirculation in diesel engines featuring late PCCI type combustion strategies", Energy Conversion and Management, vol. 105, pp. 1269-1280.

[14] Agarwal, A.K., Singh, A.P., and Maurya, R.K., 2017, "Evolution, challenges and path forward for low temperature combustion engines", Progress in Energy and Combustion Science, vol. 61, pp. 1-56.

[15] Reitz, R.D., and Duraisamy, G., 2015, "Review of high efficiency and clean reactivity controlled compression ignition (RCCI) combustion in internal combustion engines", Progress in Energy and Combustion Science, vol. 46, pp. 12-71.

[16] Pandian, M. M. and Anand, K., 2018, "Comparison of different low temperature combustion strategies in a light duty air cooled diesel engine", Applied Thermal Engineering, vol. 142, pp. 380-390.

[17] Najafabadi, M.I., Somers, B., Johansson, B., and Dam, N., 2018, “Combustion stratification study of partially premixed combustion using Fourier transform analysis of $\mathrm{OH}^{*}$ chemiluminiscence images", International Journal of Engine Research, vol. 19, pp. 1024-1035.

[18] Colban, W.F., Miles, P.C. and Oh, S., 2007, "Effect of intake pressure on performance and emissions in an automotive diesel engine operating in low temperature combustion regimes", SAE Paper No. 200701-4063.

[19] Sarangi, A.K., McTaggart-Cowan, G.P., and Garner, C.P., 2010, "The effects of intake pressure on high EGR low temperature diesel engine combustion”, SAE Paper No. 2010-01-2145.

[20] Sarangi A.K., Garner, C.P., McTaggart-Cowan, G.P., Davy, M.H, Wahab, E., and Peckham, M., 2015, "Load transient between conventional diesel operation and low-temperature combustion", IMechE Part D, Journal of Automobile Engineering, vol. 229, pp. 850-865.

[21] Cong, S., 2011, “An Experimental Study of Low Temperature Combustion in a Diesel Engine”, PhD Thesis, Loughborough University, Loughborough, UK.

[22] Sarangi, A.K., 2012, "Diesel Low Temperature Combustion- An Experimental Study", PhD Thesis, Loughborough University, Loughborough, UK.

[23] Heywood, J.B., 1988, “Internal Combustion Engines Fundamentals”, McGraw Hill Book Company, Singapore. 
[24] Sarangi, A.K., Garner, C.P., McTaggart-Cowan, G.P., Davy, M.H, Wahab, E., and Peckham, M., 2012, "Effects of engine operating parameters on diesel low temperature combustion with split fuel injection", IMechE Part D, Journal of Automobile Engineering, vol. 226, no. 9, pp. 1271-1286.

[25] Photosensor Modules H5784 Series Instruction Manual, Hamamatsu, vol. 2E, May 2007.

[26] Gaydon, A.G., 1974, “The Spectroscopy of Flames”, Chapman and Hall Ltd, London.

[27] Loughborough University instruction manual for cylinder head with endoscopic access for AVL 5402 single cylinder research engine no. 5402.055, 2009, AVL List GmbH.

[28] McTaggart-Cowan, G.P., Cong, S., Garner, C.P., Wahab, E., and Peckham, M., 2012, "Experimental study of low temperature diesel combustion sensitivity to engine operating parameters", Journal of Engineering for Gas Turbines and Power, vol. 134, pp. 082805-1-082805-11.

[29] Ogawa, H., Morita, A., Futagami, K., and Shibata, G., 2018, "Ignition delays in diesel combustion and intake gas conditions", International Journal of Engine Research, vol. 19, pp. 805-812.

[30] Jung, Y., and Bae, C., 2015, "Immaturity of soot particles in exhaust gas for low temperature diesel combustion in a direct injection compression ignition engine", Fuel, vol. 161, pp. 312-322.

[31] Wissink, M.L., Splitter, D.A., Dempsey, A.B., Curran, S.J., Kaul, B.C., and Szybist, J.P., 2017, “An assessment of thermodynamic merits for current and potential future engine operating strategies", International Journal of Engine Research, vol. 18, pp. 155-169.

[32] Carton, J., 2018, "Maximum efficiencies for internal combustion engines: thermodynamic limitations", International Journal of Engine Research, vol. 19, pp. 1005-1023.

[33] Inaba, K., Ojima, Y., Masuko, Y., Kobashi, Y., Shibata, G., and Ogawa, H., 2019, “Thermal efficiency improvement with super-charging and cooled exhaust gas recirculation in semi-premixed diesel combustion with a twin peak shaped heat release", International Journal of Engine Research, vol. 20, pp. 80-91.

[34] Cong, S., McTaggart-Cowan, G.P., Garner, C.P., Davy, M.H, Wahab, E., and Peckham, M., 2011, "Experimental Investigation of Low Temperature Diesel Combustion Processes", Journal of Combustion Science and Technology, vol. 138, pp. 1376-1400.

[35] Park, C. and Busch, S., 2018, "The influence of pilot injection on high-temperature ignition processes and early flame structure in a high-speed direct injection diesel engine", International Journal of Engine Research, vol. 19, pp. 668-681.

\section{Notation}

$\begin{array}{ll}\text { ATDC } & \text { After top dead centre } \\ { }^{\circ} \mathrm{CA} & \text { Degree crank angle } \\ \text { CA10 } & 10 \% \text { of cumulative energy release } \\ \text { CA50 } & \text { Mid-point of cumulative energy release } \\ \text { CA90 } & 90 \% \text { of cumulative energy release } \\ \text { CCD } & \text { Charge coupled device } \\ \text { CDC } & \text { Conventional diesel combustion }\end{array}$




\begin{tabular}{|c|c|}
\hline $\mathrm{CO}$ & Carbon monoxide \\
\hline $\mathrm{CO}_{2}$ & Carbon dioxide \\
\hline $\mathrm{COV}$ & Coefficient of variation \\
\hline EATS & Exhaust after-treatment system \\
\hline EGR & Exhaust gas recirculation \\
\hline EOI & End of injection \\
\hline FOV & Field of view \\
\hline FSN & Filter smoke number \\
\hline GIMEP & Gross indicated mean effective pressure \\
\hline GISFC & Gross indicated specific fuel consumption \\
\hline HSDI & High speed direct injection \\
\hline ISFC & Indicated specific fuel consumption \\
\hline LTC & Low temperature combustion \\
\hline $\mathrm{NO}_{\mathrm{X}}$ & Nitrogen oxides $\left(\mathrm{NO}\right.$ and $\left.\mathrm{NO}_{2}\right)$ \\
\hline NTC & Negative temperature coefficient \\
\hline $\mathrm{O}_{2}$ & Oxygen \\
\hline PM & Particulate matter \\
\hline PMT & Photomultiplier tube \\
\hline SCR & Selective catalytic reduction \\
\hline SOC & Start of combustion \\
\hline SOI & Start of injection \\
\hline TDC & Top dead centre \\
\hline THC & Total unburned hydrocarbons $(\mathrm{C} 1)$ \\
\hline $\mathrm{YO}_{2}$ & Intake oxygen mass fraction \\
\hline
\end{tabular}

